\title{
Birth Order and the Intrahousehold Allocation of Time and Education ${ }^{1}$
}

\author{
Mette Ejrnæs \\ Centre for Applied Microeconometrics \\ University of Copenhagen ${ }^{2}$ \\ Claus Chr. Pörtner \\ Department of Economics \\ Georgetown University ${ }^{3}$
}

October 2002

\footnotetext{
${ }^{1}$ We would like to thank Kevin Duncan, Bo Honoré, Mark Pitt, John Strauss, Finn Tarp, two anonymous referees and seminar participants at University of Colorado and George Washington University for helpful suggestions and comments. We would also like to thank Robert E. Evenson for use of the data set and for answering numerous questions about it.

${ }^{2}$ Institute of Economics, Studiestræde 6, DK-1455 Copenhagen K, Denmark, METTE.EJRnEs@ECON.KU.DK. The activities of CAM is financed by a grant from the Danish National Research Foundation.

${ }^{3}$ Washington, DC 20057, CCP6@GEORGETOWN.EDU
} 


\begin{abstract}
A potential determinant of intrahousehold distribution is the birth order of children. While a number of studies have analysed birth order effects in developed countries there are still only a few dealing with developing countries. This paper develops a model of intrahousehold allocation with endogenous fertility, which captures the relation between birth order and investment in children and shows that a birth order effect in intrahousehold allocation can arise even without assumptions about parental preferences for specific birth order children or genetic endowments varying by birth order. The important contribution is that fertility is treated as endogenous, something which other models of intrahousehold allocation have ignored despite the large literature on determinants of fertility. The implications of the model are that children with higher birth orders have an advantage over siblings with lower birth orders and that parents who are inequality averse will not have more than one child. The model furthermore shows that not taking account of the endogeneity of fertility when analysing intrahousehold allocation may seriously bias the results. The effects of a child's birth order on its human capital accumulation are analysed using a longitudinal data set from the Philippines. Contrary to most longitudinal data sets this data set covers a very long period. We are, therefore, able to examine the effects of birth order on both number of hours in school during education and completed education. The results for both are consistent with the predictions of the model.
\end{abstract}

JEL Classification Numbers: D1, I2, J2, O12. 


\section{Introduction}

The decisions made by parents affect not only a child's current well-being but also its future prospects. A prime example is the amount of schooling that a child receives. Going to school not only decreases the amount of time spent working; it is also likely to increase the future earnings capacity of the child. Uncovering how these decisions are made and what factors influence them has been an active research area in economics for many years. Focus has so far been on using differences between families to explain variation in educational attainment of children. While this approach can explain a significant portion of human resource investments it ignores the role that intrahousehold allocation plays.

The Laguna Province in the Philippines, where the data set used in this paper is from, is a good example of the importance of intrahousehold variation. ${ }^{1}$ A simple variance analysis shows that the differences among families accounts for 49 per cent of the total variation in completed education between children and that if boys and girls are considered separately, up to 60 per cent is explained by differences among families. Hence, although the interhousehold variation is clearly important there is still considerable variation within families. On average this intrahousehold variation is equal to approximately two years of schooling. Furthermore, the variance analysis indicates that the variation in years of schooling is greater among girls than boys.

Hence, one cannot satisfactorily examine parental decisions on human resource investments without analysing how resources are allocated within the family. Increasing emphasis is therefore being placed on how parents distribute their resources among children. ${ }^{2}$ One factor that has received relatively little attention is the effect of birth order on the allocation of resources. With respect to developing countries only three papers focus explicitly on this area. Birdsall $(1979)^{3}$ analyses the effect of birth order on educational attainment of children in urban Columbia. Behrman (1988b) studies the effects on child health and nutritional intake with special attention to the effects of seasonality using the Indian ICRISAT data. Horton (1988) looks also at children's nutritional status but uses data from the Bicol region of the Philippines. ${ }^{4}$

\footnotetext{
${ }^{1}$ The data are described in more detail in Section 5.

${ }^{2}$ Behrman (1997) is a review of the literature in the area. A recent example is Horowitz and Wang (2001).

${ }^{3}$ Later published in Birdsall (1991).

${ }^{4}$ Examples of studies using developed country data are Behrman and Taubman (1986)
} 
The purposes of this paper are to analyse the relation between intrahousehold allocation and birth order, which we do using a model of intrahousehold allocation with endogenous fertility, and to present evidence on the effects of birth order on intrahousehold allocation in a developing country. The plan of the paper is as follows. In Section 2 we discuss the different explanations offered for why a birth order effect can exists. Section 3 presents a model of intrahousehold distribution with endogenous fertility. The choice of the measure of birth order and various econometric issues are discussed in Section 4. In Section 5 we provide a brief description of the data set and the area in which it was collected and discusses the explanatory variables. In Section 6 the effects of birth order on completed education are estimated. The effects on time allocation are analysed in Section 7. Finally, Section 8 draws up the implications of the findings and suggests areas for future research.

\section{$2 \quad$ Why a Birth Order Effect?}

Researchers have suggested a number of potential reasons for the existence of birth order effects, and we provide a brief overview of these in this section. We divide the explanations into three categories: Constraints, household environment and biological effects. The idea behind the constraint explanation is that parents either fail to take account of financial constraints over the life cycle or that capital markets are imperfect. This makes it impossible to equalise expenditures over children. If there is a constraint on the possibility of equalising spending per child, first-born and last-born children will benefit from higher average levels of spending since they spend more time in smaller families than the middle-borns (Birdsall 1991). There may, however, be an extra dimension to this problem. Parish and Willis (1993) note that if parents' earnings increase over their life cycle this may tend to favour later-borns compared with the earlier-borns since the amount of resources is greater at the later stages of the parents' life cycle. It is also possible that the resource constraint could lead to the older children entering the labour market earlier, thereby increasing the available resources for the younger children.

Related to the resource constraint idea is the explanation offered by Birdsall (1991), who focusses on the time constraint of the mother. The basic idea is that time cannot be transferred across periods. If the amount of time a child spends with its mother matters for its human capital this would

and Kessler (1991). 
tend to favour the first-borns and the last-borns. This is tested by dividing the sample into children of working mothers and those with a non-working mother. The idea is that a working mother is not in a corner solution and should therefore be able to equalise the time spent with each child. Birdsall's results indicate that there are, indeed, no significant birth order effects for working mothers, while there are for mothers not in the labour force.

The household environment explanation says that the household environment changes with changes in the number and age of children present. It has been hypothesised that the intellectual environment is an important determinant of children's education (Zajonc 1976). If this is the case children of lower birth orders will have an advantage since they reside in households with higher average education or IQ. ${ }^{5}$ This can be compared with the Birdsall (1991) model if one substitutes attention for education. While this effect is likely to be most important for the oldest children it will also tend to place the youngest children in a better position than the middle-borns.

Biology may also create a birth order effect. One possible explanation is maternal depletion. Children of higher birth order naturally have older mothers, and older mothers tend to have children of lower birth weight. This would again tend to give the oldest children an advantage. There is, however, also a tendency for the first-born to be of lower birth weight. Countering this biologically disadvantage of the later-borns is the fact that the mother gains experience in child care with each child.

Birth order effects may also arise due to cultural factors. An example mentioned in Horton (1988), is the possibility that the oldest son is important in funeral rites. Another potential reason is the need for security in old age. Since the oldest children become economically independent first they may be the most favoured. Finally, birth order effects can also come about as a result of parents' preferences. In the model presented below the way that parents choose the number of children gives rise to a birth order effect, where the later-borns are provided with more education than earlier-borns. This does not require the parents to have special preferences for children of specific birth orders. In fact, if all parents could be forced to have the same number of children we would expect the educational attainment of these children to be the same on average and hence not to exhibit a birth order effect.

\footnotetext{
${ }^{5}$ Zajonc (1976) also discusses the effects of older children learning from teaching younger siblings and the role of spacing between siblings.
} 


\section{A Model of Intrahousehold Allocation}

Despite the attention that intrahousehold allocation has received in the literature there has been little attempt at integrating models of fertility with models of intrahousehold allocation (Behrman 1997, p. 128, f.n. 7). This is especially problematic when analysing the relation between intrahousehold allocation and birth order since birth order is the realisation of the parents' fertility decisions. Hence, this section presents a model of intrahousehold allocation of resources with endogenous fertility, where, contrary to previous models of intrahousehold allocation, such as Behrman (1988b) and Birdsall (1991), the number of children is endogenously determined by parents who take into account their budget constraint, the genetic endowments of existing children and their expectations about the genetic endowments of possible future children. Also contrary to Behrman (1988b) we do not assume that the endowments of the children or the weights they have in the utility function are in any way related to birth order. Still, it is possible to draw strong implications about the relation between the number of children, their birth order and intrahousehold allocation. One of the main conclusions of the model is that not taking account of the endogeneity of fertility can significantly bias the interpretation of the data.

To make the model tractable we assume that there only one way of investing in children and that is through their human capital. The discussion of intrahousehold allocation is often cast in terms of two special cases, the wealth model model suggested by Becker and Tomes (1976) and the separable earnings-transfers (SET) model proposed by Behrman, Pollak and Taubman (1982). Both of these "competing" models include two forms of intergenerational investment (human capital investments and direct transfers) with the difference between the two being that the wealth model assume that parents only care about the total wealth (income plus transfers), while the SET model assumes that income and transfers are separable in the parents' utility function. The main difference between the outcomes of these models is that the wealth model predicts that parents will always reinforce the genetic endowments of their children, while in the SET model parents may either reinforce, compensate or be neutral. ${ }^{6}$ In spirit the model we present is closest to the SET model in that parents have only one way of transfering

\footnotetext{
${ }^{6}$ See, however, the discussions of the models in Becker (1991), Behrman, Pollak and Taubman (1995) and Behrman (1997).
} 
resources to their children and hence can be thought of as having separable preferences between human capital and transfers, and that parents may either compensate, reinforce or be neutral with respect to their children's endowments. ${ }^{7}$ Indeed, the model is based on, and uses the same functional form, as Behrman (1988b), who also assumes only one mechanism of transfers. In the empirical section below we will discuss the possible effects of other types of transfers such as bequests in the form of land. The model also assumes that there is no feedback from one child to another either through learning as suggested by Zajonc (1976) or changes in the budget restriction (which would be the case if older children would join the labour market instead of going to school).

Each child is born with a genetic endowment $G_{i}$ which, together with the schooling input $S_{i}$, determines the human capital outcome of the child. The human capital production function is quasi-Cobb-Douglas

$$
H_{i}=G_{i} S_{i}^{\alpha} \quad i=1, \ldots, n,
$$

with diminishing marginal returns to schooling inputs $(\alpha<1)$. The children's genetic endowments and how they are created are discussed in detail below.

Parents derive utility from their $n$ children's human capital $H_{i}, \quad i=$ $1, \ldots, n$ and from other outcomes, such as parental consumption. The parents' utility function is separable between these two outcomes and the subutility function for the children's human capital is CES,

$$
U=\left\{\begin{array}{ll}
\left(\sum_{i=1}^{n} a_{i} H_{i}^{c}\right)^{1 / c} & c \leq 1, c \neq 0 \\
\prod_{i=1}^{n} H_{i}^{a_{i}} & c=0
\end{array} .\right.
$$

The parameters $a_{1}, \ldots, a_{n}$ reflect the weights parents place on each child's human capital. To simplify the discussion we assume that parents place equal weight on all children. ${ }^{8}$ Hence, a birth order effect cannot arise from different weights given to children of different birth orders.

The proportion of income allocated to children, $R$, is constant, there is a fixed cost $k$ of having a child and $p_{S}$ is the price of the schooling input.

\footnotetext{
${ }^{7}$ An alternative would be to assume that parents care about their children's consumption but are not able to transfer resources later in life through, for example, bequests. This is the method used by Horowitz and Wang (2001) who present a model of schooling and child labour with heterogeneous children which does not allow for endogenous fertility.

${ }^{8}$ Hence, $a_{i}=a, \forall i \in 1, \ldots, N$, where $N$ is the maximum number of children a family can have. This is what Behrman (1988b) refers to as equal concern.
} 
Hence, the budget constraint is given by

$$
\sum_{i=1}^{n}\left(p_{S} S_{i}+k\right) \leq R .
$$

\subsection{Genetic Endowments}

There are a number of important aspects of the model that we have not yet discussed. These are what genetic endowments are, how they are observed, how parents form expectations about future children endowments and how parents decide on fertility. All of these questions are related but we will deal with each individually to begin with.

Genetic endowments encompass a wide variety of different characteristics, some easily observed, others not. The most easily observed, both by parents and researchers, is the sex of the child. Endowments may also include other physical characteristics, such as stature (or rather potential stature). More difficult to observe for the researcher is a child's resistance to illness or its ability to convert calorie intake to body mass. ${ }^{9}$ Even more difficult to assess are innate abilities or talents.

Depending on how human capital is measured the genetic endowments discussed above will all affect the return to investing in the child. Say human capital is determined by physical strength, as would be the case in a predominately rural underdeveloped economy. A child that grows more for a given input than other children would hence have a higher return. This child may grow more either because it is less prone to illnesses, and hence do not have to spend energy on fighting diseases, or simply because he converts calories into body mass more efficiently. Hence, even though we have cast the discussion here in terms of human capital and schooling input the model can be applied to any indicator that parents care about and for which the genetic endowments of the child matter. ${ }^{10}$

The discussion of what genetic endowments are lead us to how parents observe them or rather how soon they are observed. We will assume that parents are capable of forming an opinion about the genetic endowments of

\footnotetext{
${ }^{9}$ It is, however, possible to determine weight at birth which may be a good predictor for the child's future health status.

${ }^{10}$ One obvious case is where parents care about children's future income and there is significantly different returns to investment by sex as there would be in, say, India, as discussed in Rosenzweig and Schultz (1982).
} 
a child early on in its life. While parents are generally able to observe the genetic endowments of their present children, this is not the case for future children. We assume that parents in family $f$ know the distribution of genetic endowment of their future children and that it is given by

$$
G_{i} \sim G^{f}\left(m_{i}, \sigma_{i}^{2}\right)
$$

where $m_{i}$ is the mean and $\sigma_{i}^{2}$ is the variance. Furthermore, the density function for $G^{f}$ is $g^{f}$. This distribution can vary from family to family and by birth order, although we for simplicity will assume that it does not. ${ }^{11}$ Again, the sex of the child is a good example. Without prior information a pair of parents will expect to have a slightly higher probability for a boy than for a girl. ${ }^{12}$ Parents may also have information which affect their expectations about the genetic endowment of future children, such as the presence of genetically transmitted diseases in the family. It is possible that parents update their expectations with each child, but we will not explore that possibility here.

\subsection{Parents' Decision on Fertility}

Parents decide on fertility sequentially; that is, they decide whether to have a child, observe the genetic endowment of the child if they have one and then decide whether to have an additional child and so on. Since we are mainly interested in the relation between fertility and intrahousehold allocation of resources we will focus on the final outcome and assume that the distribution of human capital inputs takes place after the fertility decisions are completed. ${ }^{13}$ This is not a serious problem if the majority of the investments in children are made after the fertility spell is completed.

As shown in Appendix A one can derive an optimal stopping rule for the

\footnotetext{
${ }^{11}$ This does not change the results as long as each family knows the distribution for each $i$ and $f$.

${ }^{12}$ The prevalent sex ratio at birth is about 105 boys per 100 girls.

${ }^{13}$ It is possible to extend the model to become a proper dynamic model but we leave that for future research.
} 
parents. Parents with $n$ children will not have additional children if

$$
\begin{aligned}
(R-n k)^{\alpha}\left[\sum_{i=1}^{n} G_{i}^{\frac{c}{1-\alpha c}}\right]^{\frac{1-\alpha c}{c}}> & \\
& (R-(n+1) k)^{\alpha} \int\left[\sum_{i=1}^{n+1} G_{i}^{\frac{c}{1-\alpha c}}\right]^{\frac{1-\alpha c}{c}} g\left(G_{n+1}\right) \mathrm{d} G_{n+1} .
\end{aligned}
$$

The implication of this stopping rule is that parents who happen to have children with high genetic endowments will stop having children earlier than parents who have children with lower genetic endowments provided the distributions of genetic endowments are the same. Say a family has drawn two children with average genetic endowments. If they decide to have a third and that child has a high genetic endowment then they are more likely to stop than a family which draw a low or average endowed third child. What follows is a birth order effect where the last child tend to do best exactly because parents chose their fertility taking into account the genetic endowment of their children and having a high ability child makes it more likely that they will have no more children. Notice that this result in no way depends on having different characteristics for children of different birth orders. ${ }^{14}$

There are two special cases that are worth mentioning. The first case is there parents preferences are quasi-Cobb-Douglas, which will arise when $c \rightarrow 0$. Section A.1.1 shows that parents will distribute their resources equally between their children and that the genetic endowment of existing children does not matter when deciding on whether to have an additional child. In some sense the model is then equal to a simplified version of the standard household model of fertility where all children are assumed to be given the same amount of resources. Since the amount of resources given to each child in the family is the same we will not see any birth order effects since genetic endowments are assumed independent of birth order, although human capital outcomes will, of course, vary within the household since the children have different endowments.

The second is when $c<0$, which we will call the inequality averse case. If parents have more than one child the they will distribute relatively more

\footnotetext{
${ }^{14}$ It is even possible to show that a birth order of the kind described here can arise if the mean endowment decreases with birth order.
} 
toward children with low endowments to compensate them. ${ }^{15}$ As shown in Section A.1.2, however, it will never be optimal to have more than one child. Hence, parents who are inequality averse will only have one child. This result has an interesting implication for empirical analyses which aim to estimate parental inequality aversion. ${ }^{16}$ It is standard in these studies to leave out one-child families when estimating inequality aversion, but if parents' fertility decision is based on their inequality aversion this will tend to bias the results toward the pure-investment case (where $c=1$ ). ${ }^{17}$ This is obviously more of a problem in developed countries than in developing countries where there are relatively few one-child families, but the result may explain why there has not been any studies that have found parents to be compensating less endowed children. ${ }^{18}$ Also, note that the result may not hold for a sample of twins. That is, parents who happen to have twin when they only planned for one child may exhibit inequality aversion, while it should not be the case for parents who have twins of higher birth orders. To our knowledge there has been no attempt of dividing the sample of twins to take account of this. ${ }^{19}$

To examine the extent of the birth order effect dependence on the inequality aversion in more detail a simulation study is presented in Tables 7 to $9 .^{20}$ Table 7 show the number of children with each birth order, while Table 8 show average schooling input and human capital outcomes by birth order together with differences from the family means. As expected there is no significant birth order effect when the inequality aversion is close to the Cobb-Douglas case. This changes as we move closer to the pure-investment case. The average human capital decreases with birth order and does so more rapidly when $c$ increases, which may appear counter-intuitive compared to

\footnotetext{
${ }^{15} \mathrm{~A}$ special case of this is Rawlsian preferences when $c=-\infty$ and the parents' utility function becomes a Leontif function. In that case parents care only about the child with the least human capital.

${ }^{16}$ For examples of these studies see Behrman et al. (1982); Behrman, Pollak and Taubman (1986), Behrman and Taubman (1986) and Behrman (1988a,b).

${ }^{17}$ Hence, the claim in Behrman (1997) that there will no selectivity bias from restricting a sample to families with at least two children does not necessarily hold.

${ }^{18}$ Behrman (1988a,b) find some evidence of compensating in the surplus season in India, but this is countered by an estimate which is very close to the pure investment case during the lean season.

${ }^{19}$ There is, of course, a potential problem in determining whether parents who have twin as their first children would have wanted two children anyway. This should, however, still be the case that are significant differences between the parents' inequality aversions.

${ }^{20}$ The background for the simulations is described in more detail in Section A.1.3.
} 
what was established above. Table 8 show also, however, that when we look at the differences to the family average human capital for each child we find a positive correlation between birth order and human capital. This is the birth order effect referred to above in which later born children tend to have a higher genetic endowment and hence also a higher human capital outcome. Again the birth order effect becomes more pronounced as the inequality aversion approaches the pure-investment case.

The implications of this are important for our further analysis. Imagine that one wanted to estimate the relation between birth order and human capital using our simulation data. Doing so without taking account of the endogeneity of fertility would lead one to say that there is a significant negative birth order effect (as long as preferences are not too close to the Cobb-Douglas case). This is, however, not correct. The correct estimation method is to take account of fertility and doing so would lead to a significant positive birth order effect. Hence, using the wrong estimation method can seriously bias the results and may even lead to exactly the opposite result of the correct one!

A second simulation exercise is presented in Table 10, which shows the effects of changing the cost of children and the amount of resources devoted to them. Increasing $R$ leads to higher fertility, while the effects on mean human capital and the measures of differences are ambiguous. The effects of increasing $k$ are a reduction in fertility and an increase in average education, although the pattern when looking only at households with two or more children is ambiguous. Not surprisingly an increase in the cost of children also leads to higher differences. Provided that the fixed cost of children increases faster than the total amount of resources devoted to children, the results are consistent with the observed development in fertility. This is consistent with $k$ being related to the female wage rate as would be the case if the main fixed cost of having a child is the time the mother spends not working. Furthermore, as well as a smaller $c$ leads to less of a birth order effect, a smaller $\alpha$ also leads to less of a birth order effect. Finally, it is possible to show that the positive birth order effect can arise even if the average genetic endowment is decreasing with birth order, although the effect will not be very pronounced.

In sum, the model presented here have shown that a birth order effect in intrahousehold allocation can arise even without assumptions about parental preferences for specific birth order children or genetic endowments varying by birth order. The important contribution is that fertility is treated as en- 
dogenous, something which other models of intrahousehold allocation have ignored despite the large literature on determinants of fertility (See, for example, Schultz 1997). The implication of the model presented is that there is no inherent preference for first- or earlier-born. Rather children with higher birth orders have an advantage over siblings of lower birth orders. This is contrary to other models of the effect of birth order on intrahousehold allocation. The model furthermore show that not taking account of the endogeneity of fertility when analysing intrahousehold allocation may seriously bias the results.

\section{Measures of Birth Order}

Previous studies of birth order effects have often focussed on completed education or some measures attempting to capture it. Instead, we analyse both completed education and the time used on school activities. In this section we discuss two issues: The choice of which measure of birth order to use and the problems associated with unobservable heterogeneity. Issues that relate specifically to either completed education or time in school are examined in the relevant sections. ${ }^{21}$

The first issue is what measure of birth order to use. Economic theory does not provide any indication of suitable measures making the choice somewhat ad hoc. The three papers mentioned in the Introduction all use different measures of birth order. Horton (1988) uses the absolute birth order of each child with the first-born child given a birth order of zero. Behrman (1988b) does not have information on the absolute birth order of the children in his sample and therefore uses the relative birth order. Finally, Birdsall (1991) employs dummies for first- and last-born children. Obviously, the absolute birth order is the most natural candidate and this is the first measure we use. The main problem with using absolute birth order is that most of the variation will be due to larger families. In order to counter this problem we

\footnotetext{
${ }^{21}$ As mentioned above there may also be other types of transfers between parents and children such as direct transfers or bequests. We unfortunately do not have data on these other transfers and therefore focus on human capital investments. Since most of the household are not wealthy or have much land (only 23 percent have any land and average landholding for those are less than an acre) we expect that the most substantial transfer of resources from parents to children take place through human capital investment. Quisumbing (1994) examines human capital investments and other intergenerational transfers in another area of the Philippines.
} 
also employ a measure of relative birth order. The relative birth order is constructed such that the first-born's relative birth order equals zero and the last-born's equals one and is defined as $\frac{p-1}{n-1}$, where $p$ is the birth order and $n$ the number of children in the family. Other approaches have also been considered and we will return to this issue in the following two sections.

The second problem arises due to the fact that what we estimate is equivalent to a demand system, conditional on the birth order of the child. This is a problem since birth order, which is a measure of fertility, is likely to be correlated with unobservable characteristics of the household. This will lead to biased results if fertility and education are determined simultaneously by the family taking into consideration these characteristics. Examples of such characteristics are the fecundity of the women and the preferences of the couple. One way to solve this problem is by using household fixed effects that control for the unobservable characteristics. ${ }^{22}$ The main drawback of this approach is that it is not possible to directly include variables that do not vary between children of the same household, such as the education of the parents or the amount of land owned. It is, however, possible to control for interactions between birth order and these variables.

While controlling for household fixed effects should reduce the problems inherent in using a conditional demand framework, it is not a perfect remedy. It is also likely that there is unobservable individual heterogeneity. If, for example, the family has a child with high potential for schooling this may lead the family to adjust their fertility objective downward and invest more resources in this child. It follows that we should ideally take into account both the individual heterogeneity and the dynamic programming aspect of fertility and education. Unfortunately, the usual way of controlling for individual heterogeneity, including individual fixed effects, is not possible in this context, because all time invariant characteristics (like birth order) are then unidentified. However, if the unobserved individual effects (including the endowment of the child) are uncorrelated with birth order, the estimates should be unbiased. For the moment we conjecture that the most important aspect is the heterogeneity at the household level and leave the individual heterogeneity and dynamic programming problem for future research.

\footnotetext{
${ }^{22}$ This is equivalent to considering differences to the family mean. Note that using random effects is not an option since that method requires that the error term and the explanatory variables are uncorrelated.
} 


\section{Data}

The data in this paper are from the Laguna Multipurpose Household Surveys. ${ }^{23}$ The first survey took place in 1975 and since then resurveys have taken place in 1977, 1982, 1985, 1990, 1992 and 1998 on a progressively smaller number of households using almost the same questionnaire. Unfortunately, the 1975 survey round is unavailable and time allocation data were not collected for the 1998 resurvey. The 1998 resurvey does, however, allow us to study the completed education of the children of the household followed throughout the first five waves. The background for the original survey is described in Evenson (1978a, Appendix) and Evenson, Popkin and Quizon (1980). Evenson (1978a) contains a collection of 13 papers using data from the Laguna Province. Other works using data from the Laguna Province include King and Evenson (1983), Evenson (1978b, 1994, 1996) and Rosenzweig and Wolpin (1986).

The Laguna Province, located south of Manila, covers a 1,759 sq. km. area, and had a population of 803,750 in 1975 with a growth rate of 2.8 per cent (See Ho 1979). It is bounded on the north by the province of Rizal, on the east by Quezon, on the west by Cavite, and on the south by Batangas. While Laguna is an inland province, it does have a big fresh water lake (Laguna de Bay) that constitutes most of the province's northern border. About 80 per cent of the total area of the province, which mainly consists of plains, with some elevated area in the northeast, is used for agriculture, and water supplies are reliable and abundant in most parts. However, heavy rains and severe storms can damage crops and other assets.

In 1975 the shortest distance between the province and Manila was about 30 kilometers. During the survey period Manila has expanded so that some areas in the northern part of the province are now within Manila's urban zone. This proximity to Manila, together with the fact that it is home to the country's largest agricultural college and the International Rice Research Institute (IRRI), as well as having fertile land, explains why Laguna is one of the more developed provinces in the Philippines. The surveyed households are located in 20 different villages or communities, also known as barangays.

The educational system in the Philippines consists of an elementary school with six grades ${ }^{24}$ a high school with four grades; a college with either four or

\footnotetext{
${ }^{23}$ The survey is actually called several different things such as the Laguna Household Studies Project or the Laguna Household Economics Survey.

${ }^{24}$ Some private schools do have a seventh grade elementary class but if a respondent
} 
five years of education; and finally post graduate study. There is mandatory schooling from the first academic year after a child reaches age seven and until completion of elementary education; that is, until the child is approximately thirteen years old. Most of the elementary schools are public and tuitionfree, but secondary schools and colleges are mostly private. The educational policy in the Philippines and its effect on the level of schooling are examined in King and Lillard (1987). Here the educational attainment is measured in years. An additional year is added if the college is left with a degree, that is four years of college education with a degree is equivalent to five years of college education without a degree. Post graduate study and post graduate study with a degree are equivalent to respectively seventeen and eighteen years of education. Some parents have received vocational training, which is taken as being equal to ten years of education.

[Table 1 about here.]

The choice of explanatory variables is partly dictated by the model presented above and partly by the availability of information in the surveys. The most important is, of course, the birth order of the children, the measure of which is discussed above. Furthermore, the sex and age of the children are also included. ${ }^{25}$ Ideally we would like to use variables that directly capture the amount of resources devoted to children and the cost of children since these play an important part in the model. ${ }^{26}$ Unfortunately, there is no direct measure of these variables in our data set. Instead we use the education of the mother and of the father and the value of the household's land holdings (measured in 10 millions of pesos). The education of the mother serves as a proxy for the cost of children since it is mainly the mother's time that goes in having and rearing the children and increasing education leads to a higher opportunity cost of time. Since the father's time is generally not involved to any great extent in the rearing of children his education can be viewed as having a pure income effect on the demand for children and human capital. The value of the household's landholding is expected to both increase the income of the household and reduce the cost of children (since they can work

has more than elementary school education it is not indicated whether he received six or seven years of elementary schooling.

${ }^{25}$ We return to the reason for including age and the interpretation of its effect in the next section.

${ }^{26}$ Denoted by $R$ and $k$ respectively in the model. 
on the land). ${ }^{27}$ As with all proxy variable one has to worry about to what extent they capture what they are supposed to. If, say, the mother's education influences not only the cost of children but also her inequality aversion, although that is not modelled here, and this preference effect is strong then one cannot use the model to draw inferences about the effect of maternal education directly.

The three household variables are all interacted with the birth order of the individual children in the household. There are two reasons for using the interaction. First, as discussed above there using a household fixed model means that the effects of all variables that do not vary within the household cannot be estimated, while it is possible to estimate the effect of the interactions. Secondly, by using the interaction terms we are able to determine whether or not the birth order effect becomes more or less important with parental education and land holdings, which makes the interactions interesting in their own right.

\section{Completed Education}

As mentioned above we analyse the effect of birth order on completed education as well as the time spent in school. This section examines completed education. First, various issues concerning the data are discussed. Secondly, we look at the within family distribution of education. Thirdly, the estimation strategy is examined and, finally, the results are presented.

The data used in this section are from the last wave of the survey. The data were collected in 1998, when most of the children in the households were adults and had completed their education. We have excluded four households because there was no information on one or both of the parents' education and one household with only one child. The final size of the sample is 790 children between 13 and 53 years of age from 126 households. Of these 790 children, 411 are boys (52 percent) and they have an average education of 8.5 years. The average length of schooling of the 379 girls is 9.7 years. This is significantly higher than that of the boys. ${ }^{28}$ In the 1998 sample 70 (or 8.8 percent) of the children are still in school. Finally, the average number of children per household is 6.6 .

\footnotetext{
${ }^{27}$ An alternative interpretation is discussed below.

${ }^{28}$ The corresponding figures for children older than 24 are 8.6 and 9.8 for boys and girls respectively.
} 
One potential problem with the data is that there may be households that have not completed their fertility. This could lead to biased estimates of the effects of birth order, especially when using the relative birth order, since the children categorised as last-born would not really be the last children. In this case, however, that is unlikely to be a problem since the average age of mothers is 54.7 years. Furthermore, the youngest mother in the sample is 41 years old and hence at the end of her reproductive period. The potential bias due to incomplete fertility spells is likely to be a problem when analysing time in school and will therefore be discussed in more detail below.

Another potential problem is that not all children have finished school. Not taking into account the fact that these children will most likely have a higher education than the one currently attributed to them, could lead to biased estimates of the effect of birth order. We have excluded children less than 13 years of age to minimise this problem.

\subsection{The Distribution of Completed Education}

Before modelling completed education we examine the distribution of educational attainment among children, especially the within family distribution. As discussed in the Introduction there is considerable variation within families. On average the variation is equal to approximately two years of schooling and is higher for girls than for boys. The within family variation is analysed by regressing the within family variation, measured by the standard deviation in educational outcomes, on a set of different family characteristics. ${ }^{29}$ This is done for the complete sample and for two sub-samples containing boys and girls, respectively. In the two sub-samples we use the variation in the educational outcomes of the sons (daughters) within a family, which implies that only families with more than one son (daughter) can be used. The results of the analysis are presented in Table 2.

[Table 2 about here.]

\footnotetext{
${ }^{29}$ Other measures of the within family variation (as the within family variance and the mean of the absolute deviation) have been applied but the results are not substantially different. The family characteristics are parental education and land holdings. Mothers have an average education of 5.5 years (standard deviation: 2.7), while fathers have an average of 5.3 years (standard deviation: 2.8). Of the 126 household, 26 own some amount of land, with an average value of land for all household of 727,357 peso (standard deviation: $3,332,842)$.
} 
The education of the mothers appears to be a very important factor in equalising the educational outcome of the children, while the education of the father and the value of land owned do not have significant impact. Dividing the sample by sex reveals, however, that the mother's education does in fact only have a significant effect on the equality of boys' education, while there is no significant effect on the equality of girls. As this section shows there is a considerable within family variation in completed education. In the following subsections we use our model of completed education to investigate how much of the differences within a family can be explained by birth order effects.

[Table 3 about here.]

\subsection{A Censored Ordered Conditional Logit Model}

Since educational attainment is inherently a discrete variable an ordered logit or an ordered probit model is often used (See for example King and Lillard 1987). We extend the standard ordered logit model to account for unobserved household specific effects and censoring. Fortunately, a clear indication of which observations are censored is available, since we know if the child is still enrolled in school. If the child is in school educational attainment is defined as censored and the censoring point is the education obtained. To formalise the model, we begin by considering a model without censoring (an ordered logit model).

Let $y_{i j}$ be the final educational attainment of child $i$ in household $j$, where $y_{i j} \in\{0, \ldots, K\}$ and $K$ is the maximal level of education. Final education is generated by a latent variable, $y_{i j}^{*}$, such that

$$
y_{i j}=\left\{\begin{array}{lll}
0 & \text { if } \quad y_{i j}^{*} \leq \theta_{1} \\
1 & \text { if } \quad \theta_{1}<y_{i j}^{*} \leq \theta_{2} \\
& \vdots \\
K & \text { if } \quad \theta_{K}<y_{i j}^{*}
\end{array} .\right.
$$

The latent variable is determined by

$$
y_{i j}^{*}=x_{i t} \beta+\mu_{j}+\varepsilon_{i j},
$$

where the vector $x_{i j}$ includes the explanatory variables, $\mu_{j}$ is a household specific effect and $\varepsilon_{i j}$ the error term. The cumulative distribution function 
of $\varepsilon_{i j}$ conditioned on $x_{i j}$ and $\mu_{j}$ is given by

$$
F(z)=\frac{\exp (z)}{1+\exp (z)}
$$

To estimate an ordered logit with fixed effects one solution is to transform the model into $K$ different logit models using the continuation regression model (see Andersen 1997, pp. 188-190). The estimation is then performed as a two step procedure. In a standard logit model with fixed effects the $\beta$ parameters can be estimated using the conditional logit approach.

The first step is to define $K$ new variables. Let $s_{i j}^{k}$ be a binary variable, equal to one if $y_{i j} \leq k$ and zero otherwise. These $K$ variables $s_{i j}^{0}, \ldots, s_{i j}^{K-1}$ follow logit models where

$$
\operatorname{Pr}\left(s_{i j}^{k}=1\right)=\operatorname{Pr}\left(y_{i j} \leq k\right)=F\left(\theta_{k+1}-x_{i j} \beta-\mu_{j}\right) \quad k=0, \ldots, K-1 .
$$

The advantage of using the $s$-variables is that it is possible to obtain a consistent estimate of $\beta$ in a logit model when conditional maximum likelihood estimation is applied (see Chamberlain 1980 or Andersen 1973). From the $K$ different $s$-variables we obtain $K$ different estimates of $\beta$.

In the second step we use minimum distance estimation to obtain one estimate of $\beta$. Let $\delta$ be a vector of the $K$ different estimates of $\beta$ such that $\delta=\left(\hat{\beta}^{(0) \prime}, \ldots, \hat{\beta}^{(K-1) \prime}\right)^{\prime}$. A new estimate of $\beta$ is found by minimising

$$
\left(\delta-\iota_{n} \otimes \beta\right)^{\prime} W\left(\delta-\iota_{n} \otimes \beta\right)
$$

where $\iota_{K}$ is a $K$ vector consisting of ones and $W$ is a positive definite matrix. The covariace matrix of $\beta$ is given by

$$
\begin{aligned}
& V(\beta)= \\
& \quad\left[\left(\iota_{n} \otimes I\right)^{\prime} W\left(\iota_{n} \otimes I\right)\right]^{-1}\left(\iota_{n} \otimes I\right)^{\prime} W V(\delta) W\left(\iota_{n} \otimes I\right)\left[\left(\iota_{n} \otimes I\right)^{\prime} W\left(\iota_{n} \otimes I\right)\right]^{-1} .
\end{aligned}
$$

In Appendix A.2 it is shown how to derive the covariance matrix of $\delta$.

The problem with censoring is that it may introduce sample selection bias, since children who are censored are also likely to be those who will receive the most education. One way of dealing with the potential sample selection is limiting the sample such that only observations that cannot be censored are used in the estimation. The underlying idea is that children aged more than 23 cannot be censored, because the maximum education (16 
years), will have been obtained at that age since schooling begins at age 7 $(23=7+16)$. Similarly, if we consider the probability of receiving 15 years of education, all children more 22 years of age will not be censored. This implies that, when estimating $\beta^{(k)}$ on the basis of $s^{k}$, only the sub-sample containing children aged more than $7+k$ can be used. Since the selection of the sample is then based on an exogenous variable, age, this method will not give rise to sample selection bias.

\subsection{Birth Order Effects and Completed Education}

By using the model presented above, it is possible to estimate the effect of birth order using the explanatory variables discussed in Section $5 .{ }^{30}$ Notice that the estimation is performed on a slightly larger data set, hence we include all children above seven. ${ }^{31}$ The estimation results are presented in Table $4 .{ }^{32}$ In column (1) and (3) absolute birth order is used, while relative birth order is used in column (2) and (4).

[Table 4 about here.]

Focussing on column (1) and (3) we have estimated a simple specification where we control for the sex of the child, year of birth and birth order. In this specification the absolute and the relative birth order have positive and very significant effects on completed education. Hence, it appears to be an advantage to be born as one of the later children. This runs contrary to most previous results on birth order, so we have also tried other specifications. Since most other studies have shown that the middle-born children are disadvantaged we tried a quadratic term for birth order, a dummy for being the first-born child together with the linear birth order term, dummies for being among the first third and the second third of the children, plus various other specifications. None of these turned out to be significant, however.

A potential reason why younger children receive more education, besides what was suggested in the model above, is the potential work load younger

\footnotetext{
${ }^{30}$ The estimation of the final $\beta$ is based on $\beta^{(4)}, \ldots, \beta^{(15)}$. The remaining $\beta^{(k)}$ 's are excluded due to very few observations.

${ }^{31}$ Summary statistics are provided in Table 1.

${ }^{32}$ For comparison, the results of the standard fixed effects estimations are presented in Table 11 in the Appendix. Censoring is taken into account in the same way as in the analysis of the distribution of completed education. See Section 6.
} 
siblings place on older children. It is, however, difficult to determine the exact reason for the behaviour. Instead, we examine whether the birth order effect is in any way related to other observable characteristics of the household. This is done by interacting birth order with the educational attainment of the mother and the father, a dummy for being a girl and the value of landholdings, if any. For both absolute and relative birth order there is a negative effect of parental education interacted with birth order. The effect, however, is sufficiently strong so that the birth order effect is nonexisting for parents with high school education (10 years) and above.

The effect of landholdings of the household is opposite to that of parental education. There is a positive and significant effect of the value of a household's landholding, so the birth order effect is more pronounced in families with more valuable landholdings. One possible explanation for this behaviour may be that the parents are trying to compensate later born children who are presumably less likely to inherit the land than their older siblings. ${ }^{33}$ Another related explanation could be that parents follow an efficient investment strategy. That would be the case if the return to education for farmers were lower than that of other jobs after a certain level of education is achieved.

In order to investigate if birth order effects are more pronauonced for girls than boys we include the interaction between birth order and a dummy for girl. The interaction terms turned out to be positive but insignificant in the specification of relative birth order, but significant and negative, although the size is small, for absolute birth order. This indicate birth order effects are less important for girls than boys.

In all columns there is a positive and significant effect of being a girl on completed schooling. While this may appear to be the opposite of what most people expect for developing countries, there are a substantial number of developing countries where this pattern can be found. ${ }^{34}$ This pattern of providing girls with more education on average than boys can also be found for the parents of the children in this sample, even if it is not as strong. As mentioned above the average education of the mothers is 5.5 years, while it is slightly less for the fathers, who have an average of 5.3 years of education. At

\footnotetext{
${ }^{33}$ Quisumbing (1994) examines the relation between land holdings and transfers in the Philippines, although in a different area than the one used in this paper.

${ }^{34}$ As discussed in Behrman, Duryea and Székely (p. 10 1999) 2/3 of the countries the analysed countries in Latin America and the Caribbean the educational level is higher for girls than for boys for the cohort born in 1970. For South Africa the schooling is about equal for men and women (Lam 1999; Anderson, Case and Lam 2001).
} 
the moment we can only speculate as to why there is this difference between boys and girls. One potential reason is that the return to women's education is higher because it is mostly women who migrate abroad to work. While it is beyond the scope of this study to examine this and other potential reasons, it is definitely an area worthy of further research.

One might imagine that what appears to be a birth order effect could simply be a cohort effect. This would be the case if the schooling system improves over the years. The younger siblings would then find themselves with better quality schooling and easier access to education, which could lead to the results presented above. We have therefore included the year of birth of the child as a control. It is surprising that the effect of year of birth is in fact negative and significant, even though the size of the effect is quite small. In the extreme example with a family with two children, born ten years apart, the total effect from year of birth would only be one-tenth of the birth order effect using the relative birth order estimates, which implies that the birth order effect dominates strongly. This is confirmed by estimating the models without the year of birth variable, in which case the birth order effects are slightly smaller but still very significant.

There are two possible explanations for the negative effect of birth cohort. First, it might be that the access and quality of schooling have decreased over

the years. Secondly, the year of birth variable is not just taking account of the cohort effect, but also of the effect of the mother's age when given birth. The reason is that in the estimation we only consider differences from the household means. Therefore, can the variable of years of birth as well be interpreted as the effect for the mother's age when giving birth to the child. Hence it is not possible to separate the two effects. If children born of younger mothers tend to do better in school that may be a possible explanation for the negative effect of year of birth. So far, however, we have not been able to successfully explain this somewhat peculiar result.

\section{Time in School}

As mentioned in the introduction and in the model section, completed education of an individual is the final outcome of a number of different factors like time spent in school, the quality of the school, the support of the family, the abilities of the child, etc. Since parents do not control all these factors, they can only influence the final education to a certain extent. When examining 
birth order effects it is interesting also to look at the effects on the time spent on school and studying, because we suspect that parents are able to control more directly the time in school of their children. However, it is not obvious that birth order effects should be stronger in time spent in school than in completed education, since time in school is only one of the inputs.

The data used in this part of the paper are based on surveys conducted in 1982, 1985, 1990 and 1992. The data contain information on how many hours each child spent in school and on other school activities in the particular week when the survey was conducted. ${ }^{35}$ For the analyses of time spent in school we have limited the sample to include only children of age 7 to 18 . The sample contains 1,122 observations from 226 different households. Since we expect the number of hours of schooling to vary with age, we have divided the children into two groups consisting of young children from 7 to 12 years old and older children from 13 to 18 years old. ${ }^{36}$ The distribution of time in school is presented in Figure 1. Almost all (more than 95 per cent) of the younger children attend school, while a large fraction (45 per cent) of older children do not.

[Figure 1 about here.]

\subsection{A Sample Selection Model}

A potential problem when analysing time in school is sample selection, since not all children attend school. In order to allow for the possibility that the choice of attending school and the decision on the number of hours spent in school are taken simultaneously we use the following sample selection framework (see Davidson and McKinnon 1993). Let $h_{i j, t}$ be the observed hours child $i$ in household $j$ spends in school in period $t$ and let $d_{i j, t}$ be a binary variable taking the value one if the child attends school in period $t$ and zero otherwise. The decisions of attending school and hours in school are determined by two latent variables $h_{i j, t}^{*}$ and $d_{i j, t}^{*}$ such that

$$
\begin{aligned}
& h_{i j, t}=h_{i j, t}^{*} \quad \text { and } \quad d_{i j, t}=1 \quad \text { if } \quad d_{i j, t}^{*}>0 \\
& h_{i j, t}=0 \quad \text { and } \quad d_{i j, t}=0 \quad \text { if } \quad d_{i j, t}^{*} \leq 0 \text {. }
\end{aligned}
$$

\footnotetext{
${ }^{35}$ Information on time allocation is only available if the child is still living at home.

${ }^{36}$ Summary statistics are provided in Table 1.
} 
We assume that the latent variables are generated by a bivariate process where we allow for a fixed household specific effect. ${ }^{37}$ The latent variables are given by

$$
\begin{aligned}
& h_{i j, t}^{*}=x_{i j, t} \beta+\mu_{j}^{h}+\varepsilon_{i j, t}^{h} \\
& d_{i j, t}^{*}=z_{i j, t} \gamma+\mu_{j}^{d}+\varepsilon_{i j, t}^{d},
\end{aligned}
$$

where $x_{i j, t}$ and $z_{i j, t}$ are explanatory variables and $\mu_{j}^{h}$ and $\mu_{j}^{d}$ are unobserved household specific effects. The conditional distributions of the error terms $\varepsilon_{i j, t}^{h}$ and $\varepsilon_{i j, t}^{d}$ are assumed to be

$$
\begin{aligned}
\varepsilon_{i j, t}^{h} \mid x_{i j, t}, \mu_{j}^{h} & \sim i i d\left(0, \sigma_{h}^{2}\right) \\
\varepsilon_{i j, t}^{d} \mid x_{i j, t}, \mu_{j}^{d} & \sim i i d\left(0, \sigma_{d}^{2}\right) .
\end{aligned}
$$

This means that the conditional error terms are identically distributed random variables with means zero. Furthermore, we allow for a potential correlation between $\varepsilon_{i j, t}^{h} \mid x_{i j, t}, \mu_{j}^{h}$ and $\varepsilon_{i j, t}^{d} \mid x_{i j, t}, \mu_{j}^{d}$.

The frequently used method for estimation in sample selection models is the Heckman (1979) two step estimator. This estimation technique does not, however, directly apply when fixed effects are present. The problem is that the Heckman procedure requires a consistent estimate of the parameters associated with the binary variable and that estimating these parameters in a fixed effects models may lead to inconsistent estimates if the number of time periods is small. ${ }^{38}$ Furthermore, identification is only achieved through the functional form if the same factors determine both participation and time in school as is the case here. Yet, in a recent article by Kyriazidou (1997) a new method is proposed to estimate sample selection models for panel data with fixed effects. Although this method is developed for models with individual fixed effects rather than household specific fixed effects the methodology can easily be modified to cover this framework.

The underlying idea of Kyriazidou's method is to use a kind of difference estimator to eliminate the fixed effects in the same way as is usually done in

\footnotetext{
${ }^{37}$ In the terms of relative birth order it is theoretically possible to estimate the model with an individual fixed effect, because the relative birth order can change from one period to the next. In practice, however, the variation in relative birth order is too small to perform the estimation with an individual fixed effect.

${ }^{38}$ The inconsistency in a logit model with fixed effects is discussed in Andersen (1973) and Chamberlain (1980).
} 
linear panel models. By using differences between pair of observations from the same households where the selection terms are equal $\left(z_{i j, t} \gamma=z_{k j, s} \gamma\right)^{39}$ or at least "close", both the selection term and the fixed effect are eliminated. The estimation is based on a weighted regression where observations with selection terms that are "close" are given more weight. In our notation

$$
\begin{aligned}
\hat{\beta} & =\left[\sum_{j=1}^{J} \frac{1}{n_{j}-1} \sum_{(i, k, t, t) \in A} \hat{\psi}_{j}\left(x_{i j, t}-x_{k j, s}\right)^{\prime}\left(x_{i j, t}-x_{k j, s}\right) d_{i j, t} d_{k j, s}\right]^{-1} \\
& \times\left[\sum_{j=1}^{J} \frac{1}{n_{j}-1} \sum_{(i, k, t, t) \in A} \hat{\psi}_{j}\left(x_{i j, t}-x_{k j, s}\right)^{\prime}\left(h_{i j, t}-h_{k j, s}\right) d_{i j, t} d_{k j, s}\right]
\end{aligned}
$$

where $n_{j}$ is the number of observations for household $j$ and $A$ is a subset containing all different combinations of the observations for household $j$. The weights $\hat{\psi}_{j}$ are a function of the "sample selection terms" and they are chosen to be given by a kernel with band width $b_{w}$ and kernel density $K$. Then,

$$
\hat{\psi}_{j}=\frac{1}{b_{w}} K\left(\frac{\left(z_{i j, t}-z_{k j, s}\right) \hat{\gamma}}{b_{w}}\right) .
$$

The normal density is used as the kernel. The band width is chosen and afterwards a bias correction estimator is constructed using the procedures described in Kyriazidou (1997). To be able to construct the weights we need a consistent estimate of $\gamma$. This is done using a conditional maximum likelihood estimator, which according to Chamberlain (1980) is a consistent estimator given that the binary variable is generated by a logit model.

A crucial assumption for using this method is that at least one of the variables determining the participation process does not enter the equation for hours. Since the mandatory schooling is from seven to completing elementary school, normally at age 12 , we expect a dummy variable for children aged seven to 12 as a good predictor for participation. ${ }^{40}$ Furthermore, we assume that this variables does not affect the time spent on school activities. Using this variable as an exclusive restriction we are able to estimate the model.

\footnotetext{
${ }^{39}$ The selection term is some function of $z_{i j, t} \gamma$.

${ }^{40}$ This seems to be confirmed by the graph.
} 


\subsection{The Estimation Results}

Except for the a dummy variable of being older than mandatory school age, we use the same explanatory variables for both participation and time in school, and the same measures of birth order as in the previous analyses. To examine the extent of the problem with incomplete fertility spells we have used both the number of children in the household for each year and the completed fertility measured in 1998 when computing the relative birth order. We do not, however, find any significant differences in the results and since using the 1998 fertility data restricts the sample size we have used the current household size. Besides the explanatory variable used for the analysis of completed education, we include age and age squared and a dummy for being aged more than $12 .^{41}$ These variables are included to control for the changes in the amount of schooling over age. ${ }^{42}$ The estimation results are reported in Tables 5 and 6 .

[Table 5 about here.]

[Table 6 about here.]

Examining the results of the participation in school very few variables are significant. The most significant variables are the age variables indicating a strong age pattern in the participation. In none of the analyses the effect of birth order is significant. This implies that birth order seems less important for the participation in school. ${ }^{43}$

When looking at the results for the number of hours the evidence is mixed. For the specification using relative birth order, the birth order variables are not significant. Therefore we concentrate the discussion to the specification using absolute birth order. In this specification we find strong and positive birth order effects. The only interaction term which has a significant impact is the interaction with the girl dummy. Since this effect is found to be negative this results are in consistent with the results for completed education, which means that birth order effects are less important for girl. Also year of birth

\footnotetext{
${ }^{41}$ The ratio participating in school drops by about 15 percentage points between 12 and 13 years old.

${ }^{42}$ Other functions of age has been tried but the results of the remaining parameters are almost unaffected.

${ }^{43}$ Like in the previous analyses of completed education other measures of birth order have also been applied.
} 
seem to have a positive and significant impact on the hours spent in school. This result is in contrast to the result found for completed education..

Commenting on the remaining estimates we find that the age variable are significant. There is positive effect on hours in school for girls although it is not significant in column (1).

To sum up, the results from the participation and hours of work are less clear than for the completed education. We find weaker evidence for birth order effects in the participation and in most of the specification of hours of school than in completed education. However, the evidence for this analysis seems to be consistent with the fact that last born are spending more time in school.

\section{Conclusion}

To our knowledge there has so far been no attempt at combining models of intrahousehold allocation and fertility decisions into one model, which is especially probelmatic when analysing the effects of birth order on intrahousehold allocation since birth order is the realisation of fertility. We have shown, using a model of intrahousehold allocation with endogenous fertility, that birth order effects can arise even without parents having stronger preferences for children with specific birth order or the endowments of the children being related to birth order. The model shows that parents tend to favour the last-born children and that it of great importance to treat fertility correctly when estimating intrahousehold allocation. Furthermore, the model provides a possible explanation for why compensatory behaviour has not been observed since the model predicts that parents which are inequality averse will only have one child.

There are two major directions in which the model could be developed in the future. The first is to introduce more explicitly the dynamic element of fertility decisions. This would allow us to analyse the importance of when the genetic endowments of children are observed by parents. The second direction is to incorporate the model in a time use framework (like the one use for standard household models), such that the decisions on consumption, labour supply, fertility and investment in children were simultaneous. ${ }^{44}$ Doing this would allow a better treatment of feedbacks between siblings, such as the

\footnotetext{
${ }^{44}$ This would make both the amount of resources devoted to children, $R$, and the costs of children, $k$, endogenous.
} 
possibility that some children work or take care of younger siblings, and the possibility that parental labour supply can change in response to the characteristics of their children.

Using a longitudinal data set from the Philippines we find strong evidence for a birth order effect in both completed education and time spent on school activities. The estimation results indicate that the last-born children receive more education than their earlier-born siblings. Furthermore, we find that the effect of birth order is less pronounced in families where the parents have more education while it is stronger in families holding land. These results tie in nicely with the results from the analysis of the within family variation in completed education. This shows that there is less variation the higher the education of the parents and more variation when the family owns more land. The findings are also consistent with the predictions of the model suggested, although they do not constitute a direct test of it. ${ }^{45}$

This paper also gives rise to a number of interesting questions that deserve more attention. First, as discussed, we have controlled for household heterogeneity but not for individual heterogeneity. Using the longitudinal aspect of the data set and a dynamic programming model, it may be possible to also control for individual heterogeneity. Secondly, the large difference between the length of boys' and girls' education should be analysed in more depth. Finally, we have suggested possible reasons for the strong effect of land holdings, but without further analysis it is not possible to provide a completely satisfactory answer. One possible beneficial approach is to look at patterns of inheritance as suggested in this paper.

\footnotetext{
${ }^{45}$ One possible way to directly test the model would be to estimate whether birth order effects exist in aptitude test scores (in the hope that these measure innate ability).
} 


\section{A Appendix}

\section{A.1 The Model}

This section shows, in detail, the implications of the model outlined in Section 3. The maximisation problem of the parents is:

$$
\begin{aligned}
\max _{n,\left\{S_{i}\right\}_{1}^{n}} U & =\left(\sum_{i=1}^{n} a_{i} H_{i}^{c}\right)^{1 / c} \quad c \leq 1, c \neq 0 \quad \text { subject to } \\
H_{i} & =G_{i} S_{i}^{\alpha} \\
R & \geq \sum_{i=1}^{n}\left(S_{i}\right)+n k \\
G_{i} & \sim G^{f}\left(m_{i}, \sigma_{i}^{2}\right) .
\end{aligned}
$$

To simplify notation assume $a_{i}=1 \forall i{ }^{46}$ For a given $n$ the optimal distribution of schooling inputs are

$$
S_{i}=(R-n k) \frac{G_{i}^{\frac{c}{1-\alpha c}}}{\sum_{j=1}^{n} G_{j}^{\frac{c}{1-\alpha c}}} .
$$

Utility is then

$$
U_{n}=(R-n k)^{\alpha}\left[\sum_{i=1}^{n} G_{i}^{\frac{c}{1-\alpha c}}\right]^{\frac{1-\alpha c}{c}} .
$$

Hence, if parents have only one child the realised utility is simply

$$
U_{1}=G_{1}(R-k)^{\alpha}
$$

which is independent of the value of $c$.

Since the problem is sequential we can solve it backwards. ${ }^{47}$ To fix ideas assume that $R=5 k$. In that case it will never be optimal to have five children, since there would not be any resources left to invest in schooling. Furthermore, assume that the genetic endowments of future children are distributed uniformly between zero and one (both included). Hence, parents

\footnotetext{
${ }^{46}$ We already assumed that the weights are equal for all children.

${ }^{47}$ It turns out that this is not really necessary, but it makes it easier to solve.
} 
with three children with genetic endowments of $G_{1}, G_{2}$ and $G_{3}$ will decide to have the fourth child when

$$
U_{3}\left(G_{1}, G_{2}, G_{3}\right)<E\left[U_{4}\left(G_{1}, G_{2}, G_{3}, G_{4}\right)\right],
$$

which translates into

$$
(R-3 k)^{\alpha}\left[\sum_{i=1}^{3} G_{i}^{\frac{c}{1-\alpha c}}\right]^{\frac{1-\alpha c}{c}}<(R-4 k)^{\alpha} \int_{0}^{1}\left[\sum_{i=1}^{4} G_{i}^{\frac{c}{1-\alpha c}}\right]^{\frac{1-\alpha c}{c}} \mathrm{~d} G_{4} .
$$

This inequality provides us with a condition on $\sum_{i=1}^{3} G_{i}^{\frac{c}{1-\alpha c}}$. If that condition is not fulfilled because the "sum" 48 of the genetic endowments of the first three children is too high then parents will not have the fourth child.

This can, for example, be seen in the case where $c=1$ and $\alpha=\frac{1}{2} \cdot{ }^{49}$ Equation (9) then becomes

$$
\begin{aligned}
2\left(\frac{R-3 k}{R-4 k}\right)^{\frac{1}{2}} & <\left(\frac{\sum_{i=1}^{3} G_{i}^{2}+1}{\sum_{i=1}^{3} G_{i}^{2}}\right)^{\frac{1}{2}} \\
& +\left(\sum_{i=1}^{3} G_{i}^{2}\right)^{\frac{1}{2}} \times \log \left(\frac{1+\left(1+\sum_{i=1}^{3} G_{i}^{2}\right)^{\frac{1}{2}}}{\left(\sum_{i=1}^{3} G_{i}^{2}\right)^{\frac{1}{2}}}\right) .
\end{aligned}
$$

Using that $R=5 k$ and solving leads to the condition

$$
\sum_{i=1}^{3} G_{i}^{2} \lesssim 0.3
$$

This condition on the sum of genetic endowments can then be used when analysing the choice whether parents with two children want a third child. If the sum of the first two children's genetic endowments is higher than that required to have four children (in our case with $c=1$ and $\alpha=.5$ this would be $\left.\sum_{i=1}^{2} G_{i}^{2} \gtrsim 0.3\right)$ then we can focus on comparing the utility of having two

\footnotetext{
${ }^{48}$ When we refer to the sum of the genetic endowments we are referring to the sum over the individual genetic endowments after they are raised to the power determined by $c$ and $\alpha$.

${ }^{49}$ The integral has a "nice" closed-form solution when $\frac{c}{1-\alpha c}=\frac{1}{2}$. The results that will be discussed do, however, hold for other values as well.
} 
children with the expected utility of having three children. ${ }^{50}$ Doing that for our example reveals that for parents to have three children it must be the case that

$$
\sum_{i=1}^{2} G_{i}^{2} \lesssim 0.62 .
$$

Of course, parents with children where the sum of the first two children's genetic endowment is less than that may have four children as well, provided that the sum of the three children's genetic endowment is less than the 0.3 found above. Finally for parents to decide to have two children the square of the first child's genetic endowment has to be less than approximately 0.95 .

Hence, what we in effect have is an optimal stopping rule. Parents will go from having $n$ children to having $n+1$ until

$$
\begin{aligned}
(R-n k)^{\alpha}\left[\sum_{i=1}^{n} G_{i}^{\frac{c}{1-\alpha c}}\right]^{\frac{1-\alpha c}{c}}> & \\
& (R-(n+1) k)^{\alpha} \int\left[\sum_{i=1}^{n+1} G_{i}^{\frac{c}{1-\alpha c}}\right]^{\frac{1-\alpha c}{c}} g\left(G_{n+1}\right) \mathrm{d} G_{n+1} .
\end{aligned}
$$

This stopping rule gets easier and easier to fulfill as the number of children increases. Hence, parents that draw very high endowment children will stop having children earlier than those that draw low endowment children (provided they have the same distribution function). There is no need to worry about the utility of having $n+2$ or more children since for the stopping rule the requirement derived from the expected utility of $n+1$ children is stronger than for $n+2$ or more as can be seen from the discussion above.

\section{A.1.1 The Cobb-Douglas Case}

At $c=0$ the utility function becomes a Cobb-Douglas function

$$
U=\prod_{i=1}^{n} H_{i}
$$

It is straightforward to show that, for a given number of children, the size of the schooling input is the same for all children. Hence, the realised utility

\footnotetext{
${ }^{50}$ The main advantage of this is that it is easier to solve.
} 
for parents with $n$ children will be

$$
U_{n}=\prod_{i=1}^{n} G_{i}\left(\frac{R-n k}{n}\right)^{n \alpha}
$$

One implication of Cobb-Douglas preferences is that when deciding on whether to have an extra child the genetic endowments of previous children do not matter. For parents with $n$ children to decide on having $n+1$ children requires that

$$
\begin{array}{r}
\int \prod_{i=1}^{n+1} G_{i}\left(\frac{R-(n+1) k}{n+1}\right)^{(n+1) \alpha} g\left(G_{n+1}\right) \mathrm{d} G_{n+1} \\
>\prod_{i=1}^{n} G_{i}\left(\frac{R-n k}{n}\right)^{n \alpha}
\end{array}
$$

After reducing, this leads to the following condition on the expected genetic endowment of the $n+1$ 'st child

$$
\int G_{n+1} g\left(G_{n+1}\right) \mathrm{d} G_{n+1}>\left(\frac{R-n k}{n}\right)^{n \alpha}\left(\frac{R-(n+1) k}{n+1}\right)^{-(n+1) \alpha} .
$$

\section{A.1.2 The Inequality Averse Case}

If $c<0$ parents with more than one child will compensate the children which have lower endowments. ${ }^{51}$ We show, however, that if $c<0$ it is never optimal to have more than one child. To simplify the notation denote $\frac{1-\alpha c}{c}$ by $\beta$. If $c<0$ then it follows that $\beta<0$. The proof is made by contradiction. Assume that it is optimal for a household to have two children. This implies by equation (5) that

$$
(R-k)^{\alpha} G_{1}<(R-2 k)^{\alpha} \int\left(G_{1}^{1 / \beta}+G_{2}^{1 / \beta}\right)^{\beta} g\left(G_{2}\right) d G_{2} .
$$

From this we must have that

$$
G_{1}<\left(\frac{R-k}{R-2 k}\right)^{\alpha} G_{1}<\int\left(G_{1}^{1 / \beta}+G_{2}^{1 / \beta}\right)^{\beta} g\left(G_{2}\right) d G_{2},
$$

\footnotetext{
${ }^{51}$ This includes the special case of Rawlsian preferences where $c=-\infty$. In this case the parents' utility function becomes a Leontif function $U=\min \left(H_{1}, \ldots, H_{n}\right)$ and they care only about the child with the least amount of human capital.
} 
since $\left(\frac{R-k}{R-2 k}\right)^{\alpha}>1$, which follows from $\alpha>0$.

To prove the contradiction we show that

$$
\left(G_{1}^{1 / \beta}+G_{2}^{1 / \beta}\right)^{\beta}<G_{1}
$$

First notice that the function

$$
f(x)=\left(G_{1}^{1 / \beta}+x\right)^{\beta}, \quad x \geq 0,
$$

is a monotonic decreasing function. ${ }^{52}$ This implies that $\left(G_{1}^{1 / \beta}+G_{2}^{1 / \beta}\right)^{\beta}<$ $\left(G_{1}^{1 / \beta}\right)^{\beta}=G_{1}$. Substituting this expression in to

$$
\int\left(G_{1}^{1 / \beta}+G_{2}^{1 / \beta}\right)^{\beta} g\left(G_{2}\right) d G_{2}<\int G_{1} g\left(G_{2}\right) d G_{2}=G_{1}
$$

However if we compare this with equation (17) we have a contradiction. Hence, it will never be optimal to have more than one child.

\section{A.1.3 Simulation Study}

This subsection describes the simulation study. All of the simulations are based on 2000 households and with the genetic endowments uniformly distributed between 1 and 99. For Tables 7 to 9 each household has 100 units of resources $(R=100)$, the fixed cost of a child is 10 units $(k=10)$ and $\alpha=0.9$. The simulations in are done with $c=0.25,0.5,0.75$ and 1 . These values are chosen because they lie in the range of the estimates Behrman (1988b) found. The maximum number of children is ten (since $R=100$ and $k=10)$.

Table 7 shows the number of children with a specific birth order. No family has more than eight children and as inequality aversion falls ( $c$ increases) the number of children goes down. Hence, a little less than 40 per cent of the household have only one child and only three households have eight children.

[Table 7 about here.]

\footnotetext{
${ }^{52}$ This can easily be seen from $\frac{\partial f}{\partial x}=\beta\left(G_{1}^{1 / \beta}+x\right)^{\beta-1}<0$ for all $x \geq 0$.
} 
The first part of Table 8 shows the average schooling input by birth order and the difference from the family mean in schooling input. The second part shows the average human capital of the children by birth order and the difference to the family mean. For low levels of $c$ there is an equal distribution of schooling inputs and consequently also an equal distribution of human capital by birth order. Looking, however, at $c=1$ the average schooling input and the human capital outcome decrease with birth order. This pattern is, however, completely reversed if we look at differences to the family mean. Then higher birth order children tend to received more than their earlier born children.

[Table 8 about here.]

Table 9 summaries the information from the two previous tables by showing how fertility, mean schooling input and differences in schooling input and human capital between first and last born children and from either to the family mean. Again we can see that as inequality aversion decreases the children of higher birth orders do better than their older siblings.

[Table 9 about here.]

Finally, Table 10 show how the summary statistics presented in Table 9 change when the amount of resources devoted to children and the cost of children changes. The simulations are again based on 2000 households with $\alpha=0.9$ and the inequality aversion is fixed at $c=0.75$. The cost of children is either $k=10$ or $k=20$ and the amounts of resources are $R=80, R=100$ and $R=120$. All combinations of cost and resources are shown. As in Table 9 fertility and mean human capital (all) are calculated over all families, while the other measures are for families with two or more children.

[Table 10 about here.]

\section{A.2 The Covariance Matrix of $\delta=\left(\beta^{(0)}, \beta^{(1)}, \ldots, \beta^{(K-1)}\right)$}

When estimating the covariance of $\delta$ we use the framework of moment conditions. Let $d_{i j}^{(k)}$ be an indicator of whether the observation of child $j$ in household $i$ is used in the estimation of $\beta^{(k)}$. The observation is used if it is 
uncensored and if there exists some variation in the outcome of $s_{i j}^{(k)}$ within the household, which formally can be written as

$$
\begin{aligned}
\operatorname{age}_{i j} & >k+7 \\
\exists j, l \quad \text { such } s_{i j}^{(k)} & \neq s_{i l}^{(k)} \text { and age } \text { age }_{i j}, \text { age }_{i l}>7
\end{aligned}
$$

The probability of $s_{i j}^{(k)}=1$ given the total outcome for household $i$ is denoted $p_{i j}^{(k)}$ :

$$
p_{i j}^{(k)}=\operatorname{Pr}\left(s_{i j}^{(k)}=1 \mid \sum_{j=1}^{n_{i}} d_{i j}^{(k)} s_{i j}^{(k)}\right),
$$

where $n_{i}$ is the number of observations in household $i$. Now we can define the moment condition for each observation

$$
l_{i j}^{(k)}=d_{i j}^{(k)} \frac{\left(s_{i j}^{(k)}-p_{i j}^{(k)}\right)}{p_{i j}^{(k)}\left(1-p_{i j}^{(k)}\right)} \frac{\partial p_{i j}^{(k)}}{\partial \beta^{(k)}},
$$

such that the unconditional expectations of $l_{i j}^{(k)}$ equals zero, $E\left(l_{i j}^{(k)}\right)=0$. The covariance matrix of $\delta$ can then be derived from $l=\left(l^{(0)}, \ldots, l^{(K-1)}\right)$ and is given by

$$
V(\delta)=D^{-1}\left(l^{\prime} l\right) D^{-1}
$$

where $D$ is a bloc-diagonal matrix and each bloc consists of

$$
D^{(k)}=\frac{\partial l^{(k)}}{\partial \beta^{(k)}} .
$$

[Table 11 about here.] 


\section{References}

Andersen, Erling B. (1973) Conditional Inference and Models for Measuring (Copenhagen: Mentalhygiejnisk Forlag)

- (1997) Introduction to the Statistical Analysis of Categorical Data (Berlin: Springer)

Anderson, Kermyt, Anne Case, and David Lam (2001) 'Causes and consequences of schooling outcomes in south africa: Evidence from survey data.' PSC Research Report 01-490, Population Studies Center, University of Michigan, October

Becker, Gary S. (1991) A Treatise on the Family, enlarged ed. (Cambridge: Harvard University Press)

Becker, Gary S., and Nigel Tomes (1976) 'Child endowments and the quantity and quality of children.' The Journal of Political Economy 84(4, Part 2), S143-S162

Behrman, Jere R. (1988a) 'Intrahousehold allocation of nutrients in rural India: Are boys favored? do parents exhibit inequality aversion?' Oxford Economic Papers 40, 32-54

_ (1988b) 'Nutrition, health, birth order and seasonality: Intrahousehold allocation among children in rural India.' Journal of Development Economics $28(1), 43-62$

_ (1997) 'Intrahousehold distribution and the family.' In Handbook of Population and Family Economics, ed. Mark R. Rosenzweig and Oded Stark, vol. 1A (Amsterdam: Elsevier Science B.V.) pp. 125-187

Behrman, Jere R., and Paul Taubman (1986) 'Birth order, schooling, and earnings.' Journal of Labor Economics. Part 4(3), S121-45

Behrman, Jere R., Robert A. Pollak, and Paul Taubman (1982) 'Parental preferences and provision for progeny.' Journal of Political Economy $90(1), 52-73$

_ (1986) 'Do parents favor boys?' International Economic Review. February $27(1), 33-54$ 
_ (1995) 'The wealth model: Efficiency in education and distribution in the family.' In From Parent to Child: Intrahousehold Allocations and Intergenerational Relations in the United States, ed. Jere R. Behrman, Robert A. Pollak, and Paul Taubman (Chicago, IL: University of Chicago Press)

Behrman, Jere R., Suzanne Duryea, and Miguel Székely (1999) 'Schooling investments and aggregate conditions: A household survey-based approach for latin america and the caribbean.' Working Paper 407, Inter-American Development Bank, Office of the Chief Economist, November

Birdsall, Nancy (1979) 'Siblings and schooling in urban colombia.' Phd, Yale University

_ (1991) 'Birth order effects and time allocation.' In Research in population economics. A Research Annual., ed. T. Paul Schultz, vol. 7 (Greenwich, Conn and London: JAI Press) pp. 191-213

Chamberlain, Gary (1980) 'Analysis of covariance with qualitative data.' Review of Economic Studies 47(1), 225-238

Davidson, Russell, and James G. McKinnon (1993) Estimation and Inference in Econometrics (Oxford: Oxford University Press)

Evenson, Robert E. (1978a) 'Symposium on household economics. Philippine household economics: An introduction to the symposium papers.' The Philippine Economic Journal

_ (1978b) 'Time allocation in rural Philippine households.' American Journal of Agricultural Economics 60, 322-330

_ (1994) 'Marriage in rural Philippine households.' Journal of Philippine Development 38(1 and 2), 411-428

- (1996) 'Ability, schooling and occupational choice in philippine rural households.' In Choice, Growth and Development: Emerging and Enduring Issues, ed. Emmanuel S. de Dios and Raul V. Fabella (Quezon City: University of the Philippines Press) pp. 193-219

Evenson, Robert E., Barry M. Popkin, and Elizabeth K. Quizon (1980) 'Nutrition, work, and demographic behaviour in rural Philippine households. a synopsis of several Laguna household studies.' In Rural Household Studies 
in Asia, ed. Hans P. Binswanger, Robert E. Evenson, Cecilia A. Florencio, and Benjamin N. F. White (Singapore: Singapore University Press)

Heckman, James J. (1979) 'Sample selection bias as a specification error.' Econometrica 47(1), 153-161

Ho, Teresa J. (1979) 'Time costs of child rearing in the rural Philippines.' Population and Development Review 5(4), 643-662

Horowitz, Andrew W., and Jian Wang (2001) 'Favorite son? Specialized child laborers and students in poor LDC households.' Mimeo, Department of Economics, Sam M. Walton College of Business, University of Arkansas

Horton, Susan (1988) 'Birth order and child nutritional status: Evidence from the Philippines.' Economic Development and Cultural Change 36(2), 341354

Kessler, Daniel (1991) 'Birth order, family size, and achievement: Family structure and wage determination.' Journal of Labor Economics 9(4), 413426

King, Elizabeth, and Robert E. Evenson (1983) 'Time allocation and home production in Philippine rural households.' In Women and Poverty in the Third World, ed. Mayra Buvinic, Margaret A. Lycette, and William Paul McGreevey (Baltimore and London: The Johns Hopkins University Press) pp. 35-61

King, Elizabeth M., and Lee A. Lillard (1987) 'Education policy and schooling attainment in Malaysia and the Philippines.' Economics of Education Review 6(2), 167-181

Kyriazidou, Ekaterini (1997) 'Estimation of a panel data sample selection model.' Econometrica 65(6), 1335-1364

Lam, David (1999) 'Generating extreme inequality: Schooling, earnings, and intergenerational transmission of human capital in South Africa and Brazil.' PSC Research Report 99-439, Population Studies Center, University of Michigan, August

Parish, William L., and Robert J. Willis (1993) 'Daughters, education, and family budgets: Taiwan experiences.' Journal of Human Resources 28(4), 863-898 
Quisumbing, Agnes R. (1994) 'Intergenerational transfers in Philippine rice villages: Gender differences in traditional inheritance customs.' Journal of Development Economics 43(2), 167-95

Rosenzweig, Mark R., and Kenneth I. Wolpin (1986) 'Evaluating the effects of optimally distributed public programs: Child health and family planning interventions.' American Economic Review 76, 470-482

Rosenzweig, Mark R., and T. Paul Schultz (1982) 'Market opportunities, genetic endowments, and intrafamily resource distribution: Child survival in rural india.' American Economic Review 72(4), 803-15

Schultz, T. Paul (1997) 'Demand for children in low income countries.' In Handbook of Population and Family Economics, ed. Mark R. Rosenzweig and Oded Stark, vol. 1A (Amsterdam: Elsevier Science B.V.) pp. 349-430

Zajonc, R. B. (1976) 'Family configuration and intelligence.' Science 192(4236), 227-236 
Table 1: Summary Statistics

\begin{tabular}{lrrrr} 
& \multicolumn{2}{c}{1998} & \multicolumn{2}{c}{$1982-1992$} \\
& Mean & St.d. & Mean & St.d. \\
\hline Years of Education & 8.89 & 3.43 & & \\
Hours of school (per week) & & & 31.41 & 19.72 \\
Year of Birth & 1970 & 8.85 & 1973 & 4.63 \\
Age & 28.18 & 8.35 & 13.02 & 3.26 \\
Girls & 0.47 & 0.50 & 0.47 & 0.50 \\
Birth Order & 4.41 & 2.80 & 5.04 & 2.87 \\
Mother's Education (in years) & 4.96 & 2.41 & 5.03 & 2.35 \\
Father's education (in years) & 4.79 & 2.72 & 4.83 & 2.68 \\
Landowners & 0.23 & 0.42 & 0.10 & 0.30 \\
Value of land Owned $^{a}$ & 0.88 & 0.83 & 1.10 & 1.55 \\
Observations $^{a}$ & 817 & & 1470 & \\
\hline
\end{tabular}

Note. ${ }^{a}$ in 10 millions of pesos 
Table 2: Within Family Variation in Years of Schooling ${ }^{a}$

\begin{tabular}{lccc} 
& \multicolumn{3}{c}{ OLS } \\
& All & Boys & Girls \\
\hline Mother's Education & -0.105 & -0.209 & -0.050 \\
& $(0.040)^{* * *}$ & $(0.058)^{* * *}$ & $(0.051)$ \\
Father's Education & -0.028 & -0.039 & -0.033 \\
& $(0.039)$ & $(0.055)$ & $(0.045)$ \\
Value of Land Owned & 0.335 & 0.109 & -0.200 \\
& $(0.300)$ & $(0.368)$ & $(0.326)$ \\
Constant & 2.690 & 3.038 & 2.286 \\
& $(0.242)^{* * *}$ & $(0.365)^{* * *}$ & $(0.280)^{* * *}$ \\
$\mathrm{R}^{2}$ & 0.09 & 0.14 & 0.03 \\
Observations & 124 & 97 & 101 \\
\hline
\end{tabular}

Note. - Standard errors in parentheses.

a : Measured by the standard deviation of schooling within a family.

* Significant at the 10 percent level.

** Significant at the 5 percent level.

*** Significant at the 1 percent level. 
Table 3: Mean Education by Birth Order

\begin{tabular}{cccccrc} 
& \multicolumn{2}{c}{ All } & \multicolumn{2}{c}{ Boys } & \multicolumn{2}{c}{ Girls } \\
Birth Order & Mean & Obs & Mean & Obs. & Mean & Obs. \\
\hline 1 & 9.23 & 125 & 8.57 & 58 & 9.80 & 67 \\
2 & 9.23 & 124 & 8.40 & 60 & 10.01 & 64 \\
3 & 9.13 & 115 & 8.42 & 61 & 9.92 & 54 \\
4 & 8.78 & 104 & 8.20 & 62 & 9.71 & 41 \\
5 & 9.47 & 87 & 8.81 & 48 & 10.28 & 39 \\
6 & 9.13 & 69 & 8.96 & 31 & 9.26 & 38 \\
7 & 9.07 & 53 & 8.89 & 28 & 9.28 & 25 \\
8 & 8.67 & 40 & 8.50 & 24 & 8.94 & 16 \\
9 & 9.00 & 27 & 9.29 & 17 & 8.50 & 12 \\
10 & 8.66 & 22 & 8.00 & 10 & 9.58 & 12 \\
11 & 7.64 & 14 & 6.00 & 6 & 8.80 & 8 \\
12 & 7.8 & 5 & 6.33 & 3 & 10.00 & 2 \\
13 & 11.00 & 3 & 11.00 & 1 & 1.00 & 2 \\
14 & 12.00 & 1 & 12.00 & 1 &. & 0 \\
\hline
\end{tabular}


Table 4: Completed Education

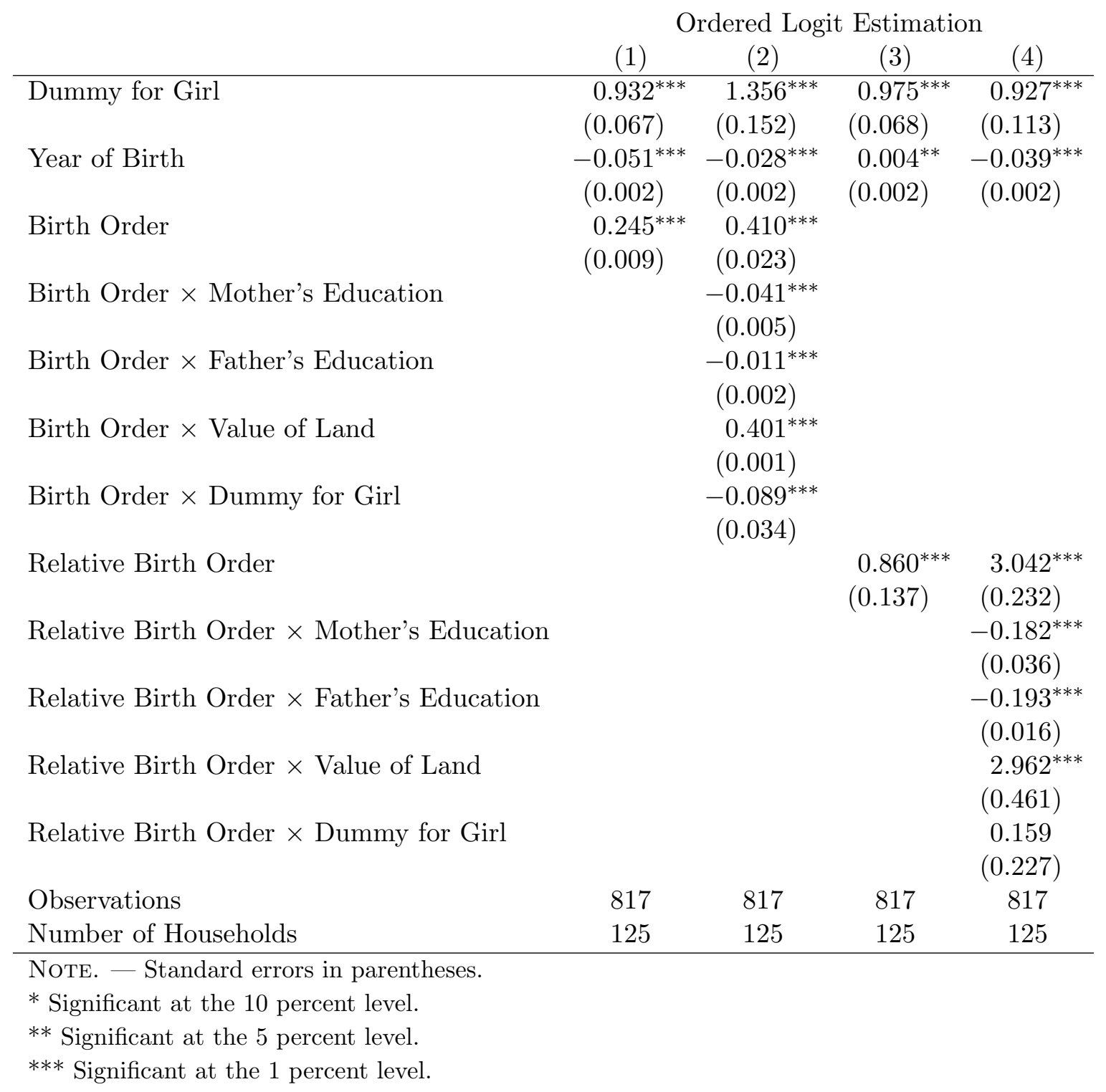


Table 5: Participation in School ${ }^{a}$

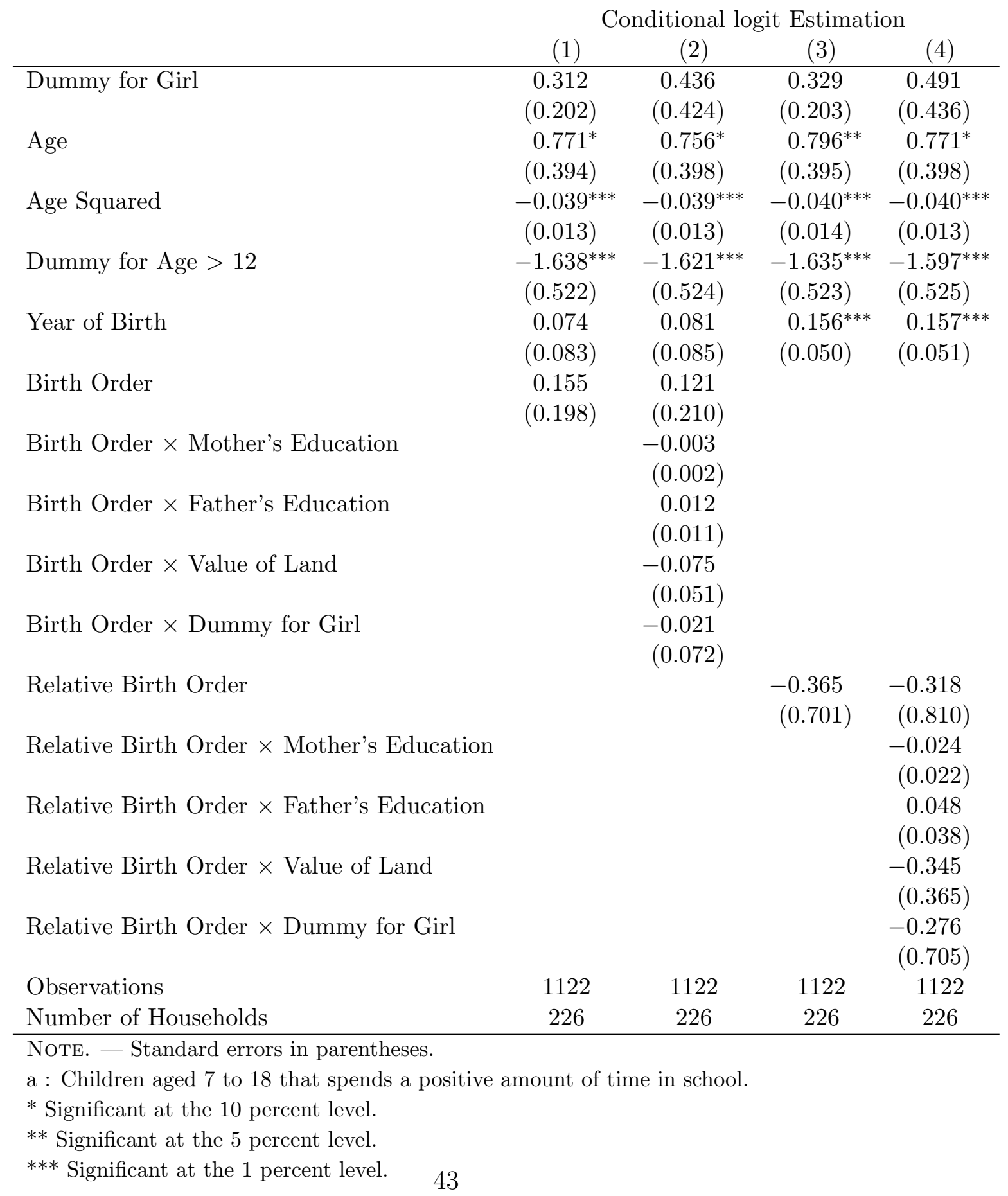


Table 6: Time Spent on School Activities ${ }^{a}$

\begin{tabular}{|c|c|c|c|c|}
\hline & \multicolumn{4}{|c|}{ Kyriazidou's Method } \\
\hline & $(1)$ & $(2)$ & $(3)$ & $(4)$ \\
\hline \multirow[t]{2}{*}{ Dummy for Girl } & $1.228^{*}$ & $7.915^{* * *}$ & $1.376^{* *}$ & $3.909^{* *}$ \\
\hline & $(0.719)$ & $(1.467)$ & $(0.653)$ & $(1.928)$ \\
\hline \multirow[t]{2}{*}{ Year of Birth } & $0.947^{* * *}$ & 0.560 & $2.461^{* * *}$ & $2.002^{* * *}$ \\
\hline & $(0.346)$ & $(0.369)$ & $(0.281)$ & $(0.280)$ \\
\hline \multirow[t]{2}{*}{ Age } & $4.805^{* *}$ & $5.054^{* * *}$ & $6.435^{* * *}$ & $4.437^{* *}$ \\
\hline & $(1.939)$ & $(1.872)$ & $(1.751)$ & $(1.787)$ \\
\hline \multirow[t]{2}{*}{ Age Squared } & -0.092 & -0.106 & $-0.198^{* *}$ & -0.104 \\
\hline & $(0.095)$ & $(0.091)$ & $(0.086)$ & $(0.087)$ \\
\hline \multirow[t]{2}{*}{ Birth Order } & $2.096^{* *}$ & $3.543^{* * *}$ & & \\
\hline & $(0.886)$ & $(0.970)$ & & \\
\hline \multirow[t]{2}{*}{ Birth Order $\times$ Mother's Education } & & 0.019 & & \\
\hline & & $(0.021)$ & & \\
\hline \multirow[t]{2}{*}{ Birth Order $\times$ Father's Education } & & 0.018 & & \\
\hline & & $(0.026)$ & & \\
\hline \multirow[t]{2}{*}{ Birth Order $\times$ Value of Land } & & 0.204 & & \\
\hline & & $(0.136)$ & & \\
\hline \multirow[t]{2}{*}{ Birth Order $\times$ Dummy for Girl } & & $-1.116^{* * *}$ & & \\
\hline & & $(0.176)$ & & \\
\hline \multirow[t]{2}{*}{ Relative Birth Order } & & & -8.712 & -4.428 \\
\hline & & & $(2.452)$ & $(3.532)$ \\
\hline \multirow[t]{2}{*}{ Relative Birth Order $\times$ Mother's Education } & & & & -0.172 \\
\hline & & & & $(0.114)$ \\
\hline \multirow[t]{2}{*}{ Relative Birth Order $\times$ Father's Education } & & & & $0.163^{* *}$ \\
\hline & & & & $(0.065)$ \\
\hline \multirow[t]{2}{*}{ Relative Birth Order $\times$ Value of Land } & & & & 0.135 \\
\hline & & & & $(2.881)$ \\
\hline \multirow[t]{2}{*}{ Relative Birth Order $\times$ Dummy for Girl } & & & & $-4.653^{*}$ \\
\hline & & & & $(2.473)$ \\
\hline Observations & 1470 & 1470 & 1470 & 1470 \\
\hline Number of Households & 201 & 201 & 201 & 201 \\
\hline
\end{tabular}

Note. - Standard errors in in parentheses.

a : Number of hours spent in school by children aged 7 to 18 .

* Significant at the 10 percent level.

** Significant at the 5 percent level.

*** Significant at the 1 percent level. 
Table 7: Simulation - Number of Children

\begin{tabular}{clccc} 
Birth Order & $\mathrm{c}=0.25$ & $\mathrm{c}=0.5$ & $\mathrm{c}=0.75$ & $\mathrm{c}=1.0$ \\
\hline 1 & 2000 & 2000 & 2000 & 2000 \\
2 & 2000 & 2000 & 2000 & 1253 \\
3 & 2000 & 2000 & 1510 & 753 \\
4 & 2000 & 2000 & 808 & 395 \\
5 & 2000 & 1961 & 334 & 197 \\
6 & 2000 & 1011 & 90 & 75 \\
7 & 2000 & 89 & 10 & 15 \\
8 & 1918 & 2 & 0 & 3 \\
\hline 53 otes: 2000 households with $R=100, k=10$ and $\alpha=0.9$.
\end{tabular}


Table 8: Simulation - Schooling and Human Capital

\begin{tabular}{ccccccccc} 
& \multicolumn{9}{c}{ Schooling Input } \\
& \multicolumn{9}{c}{ Average } & \multicolumn{5}{c}{ Difference to Family Mean } \\
Birth Order & $\mathrm{c}=0.25$ & $\mathrm{c}=0.5$ & $\mathrm{c}=0.75$ & $\mathrm{c}=1.0$ & $\mathrm{c}=0.25$ & $\mathrm{c}=0.5$ & $\mathrm{c}=0.75$ & $\mathrm{c}=1.0$ \\
\hline 1 & 1.9 & 5.5 & 13.4 & 23.2 & -0.0 & -0.1 & -1.7 & -9.0 \\
2 & 1.9 & 5.5 & 13.3 & 20.7 & -0.0 & -0.1 & -1.7 & 3.6 \\
3 & 1.9 & 5.6 & 12.8 & 20.5 & 0.0 & -0.0 & 1.2 & 9.1 \\
4 & 1.9 & 5.6 & 11.6 & 17.1 & -0.0 & -0.1 & 3.2 & 9.2 \\
5 & 1.9 & 5.6 & 11.5 & 15.9 & -0.0 & -0.0 & 5.4 & 10.1 \\
6 & 1.9 & 5.2 & 11.1 & 14.8 & -0.0 & 0.7 & 6.7 & 10.5 \\
7 & 1.9 & 4.5 & 6.8 & 9.3 & -0.0 & 1.5 & 3.8 & 6.4 \\
8 & 1.9 & 4.5 & & 9.4 & 0.0 & 2.6 & & 7.5 \\
\hline
\end{tabular}

Human Capital Outcome

Average Difference to Family Mean

\begin{tabular}{cccccrrrr} 
Birth Order & $\mathrm{c}=0.25$ & $\mathrm{c}=0.5$ & $\mathrm{c}=0.75$ & $\mathrm{c}=1.0$ & $\mathrm{c}=0.25$ & $\mathrm{c}=0.5$ & $\mathrm{c}=0.75$ & $\mathrm{c}=1.0$ \\
\hline 1 & 98.7 & 292.2 & 733.3 & 1229.7 & -0.9 & -11.1 & -110.6 & -495.6 \\
2 & 98.6 & 293.7 & 729.2 & 1109.7 & -0.9 & -9.6 & -114.7 & 198.1 \\
3 & 100.1 & 300.2 & 699.7 & 1105.5 & 0.5 & -3.1 & 86.2 & 510.4 \\
4 & 98.6 & 293.8 & 623.2 & 897.5 & -0.9 & -9.5 & 209.0 & 501.0 \\
5 & 98.9 & 294.7 & 619.4 & 837.0 & -0.6 & -1.0 & 334.8 & 551.8 \\
6 & 98.9 & 270.6 & 610.8 & 803.0 & -0.7 & 58.0 & 417.5 & 598.7 \\
7 & 99.1 & 226.0 & 328.1 & 535.9 & -0.5 & 110.1 & 219.1 & 408.1 \\
8 & 99.3 & 198.2 & & 387.4 & 4.1 & 134.0 & & 319.2 \\
\hline
\end{tabular}

Notes: 2000 households with $R=100, k=10$ and $\alpha=0.9$. 
Table 9: Simulation - Summary Statistics

\begin{tabular}{lcrrr} 
& $c=0.25$ & $\mathrm{c}=0.5$ & $\mathrm{c}=0.75$ & $\mathrm{c}=1.0$ \\
\hline Fertility & 7.96 & 5.53 & 3.38 & 2.35 \\
& \multicolumn{4}{c}{ Schooling } \\
Mean Schooling Input (all) & 1.90 & 5.67 & 15.06 & 32.18 \\
Mean Schooling Input (2+) & 1.90 & 5.67 & 15.06 & 17.14 \\
First-born to family average & -0.00 & -0.13 & -1.68 & -14.29 \\
Last-born to family average & -0.02 & 0.50 & 4.57 & 22.25 \\
Last-born - first-born & 0.03 & 0.64 & 6.24 & 36.54 \\
& \multicolumn{5}{c}{ Human Capital } \\
Mean Human Capital (all) & 99.55 & 303.34 & 843.92 & 1725.29 \\
Mean Human Capital (2+) & 99.55 & 303.34 & 843.92 & 911.59 \\
First-born to family average & -0.88 & -11.10 & -110.61 & -791.03 \\
Last-born to family average & 3.92 & 41.74 & 298.45 & 1228.11 \\
Last-born - first-born & 4.80 & 52.83 & 409.06 & 2019.14 \\
\hline Notes: 2000 households with $R=100, k=10$ & and $\alpha=0.9$.
\end{tabular}


Table 10: Simulation - Resources and Costs of Children

\begin{tabular}{lrrrrrr} 
& \multicolumn{2}{c}{$\mathrm{R}=80$} & \multicolumn{2}{c}{$\mathrm{R}=100$} & \multicolumn{2}{c}{$\mathrm{R}=120$} \\
& $\mathrm{k}=10$ & $\mathrm{k}=20$ & $\mathrm{k}=10$ & $\mathrm{k}=20$ & $\mathrm{k}=10$ & $\mathrm{k}=20$ \\
\hline Fertility & 2.70 & 1.58 & 3.38 & 1.82 & 4.03 & 2.10 \\
& & \multicolumn{5}{c}{ Schooling } \\
Mean Schooling Input (All) & 17.17 & 26.20 & 15.06 & 30.12 & 14.79 & 32.19 \\
Mean Schooling Input (2+) & 13.47 & 12.34 & 15.06 & 16.29 & 14.79 & 19.56 \\
First-born to family average & -3.07 & -6.08 & -1.68 & -7.04 & -1.69 & -7.37 \\
Last-born to family average & 5.34 & 6.53 & 4.57 & 8.43 & 5.40 & 9.87 \\
Last-born - first-born & 8.41 & 12.60 & 6.24 & 15.47 & 7.09 & 17.24 \\
& & \multicolumn{5}{c}{ Human Capital } \\
Mean Human Capital (All) & 975.20 & 1293.45 & 843.92 & 1534.55 & 830.94 & 1680.88 \\
Mean Human Capital (2+) & 723.86 & 522.48 & 843.92 & 733.24 & 830.94 & 927.51 \\
First-born to family average & -206.72 & -345.46 & -110.61 & -416.11 & -111.17 & -445.51 \\
Last-born to family average & 350.28 & 371.18 & 298.45 & 492.96 & 351.43 & 587.01 \\
Last-born - first-born & 557.00 & 716.65 & 409.06 & 909.07 & 462.60 & 1032.52 \\
\hline
\end{tabular}

Notes: 2000 households with $\alpha=0.9$ and $c=0.75$. 
Table 11: Completed Education

Fixed Effects Estimation

\begin{tabular}{|c|c|c|c|c|}
\hline & (1) & $(2)$ & (3) & (4) \\
\hline Dummy for Girl & $\begin{array}{l}0.929^{* * *} \\
(0.181)\end{array}$ & $\begin{array}{l}1.239^{* * *} \\
(0.334)\end{array}$ & $\begin{array}{l}0.929^{* * *} \\
(0.183)\end{array}$ & $\begin{array}{l}1.064^{* * *} \\
(0.316)\end{array}$ \\
\hline Year of Birth & $\begin{array}{c}-0.137^{* * *} \\
(0.044)\end{array}$ & $\begin{array}{c}-0.123^{* * *} \\
(0.045)\end{array}$ & $\begin{array}{c}-0.011 \\
(0.031)\end{array}$ & $\begin{array}{r}-0.062^{*} \\
(0.033)\end{array}$ \\
\hline Birth Order & $\begin{array}{l}0.429^{* * *} \\
(0.111)\end{array}$ & $\begin{array}{l}0.674^{* * *} \\
(0.135)\end{array}$ & & \\
\hline Birth Order $\times$ Mother's Education & & $\begin{array}{r}-0.030^{*} \\
(0.017)\end{array}$ & & \\
\hline Birth Order $\times$ Father's Education & & $\begin{array}{l}-0.034^{* *} \\
(0.014)\end{array}$ & & \\
\hline Birth Order $\times$ Value of Land & & $\begin{array}{c}0.331^{* *} \\
(0.129)\end{array}$ & & \\
\hline Birth Order $\times$ Dummy for Girl & & $\begin{array}{c}-0.074 \\
(0.063)\end{array}$ & & \\
\hline Relative Birth Order & & & $\begin{array}{c}0.765 \\
(0.564)\end{array}$ & $\begin{array}{l}4.162^{* * *} \\
(1.009)\end{array}$ \\
\hline Relative Birth Order $\times$ Mother's Education & & & & $\begin{array}{c}-0.269^{* *} \\
(0.112)\end{array}$ \\
\hline Relative Birth Order $\times$ Father's Education & & & & $\begin{array}{c}-0.250^{* *} \\
(0.103)\end{array}$ \\
\hline Relative Birth Order $\times$ Value of Land & & & & $\begin{array}{l}1.511^{* *} \\
(0.766)\end{array}$ \\
\hline Relative Birth Order $\times$ Dummy for Girl & & & & $\begin{array}{c}-0.302 \\
(0.544)\end{array}$ \\
\hline Observations & 790 & 790 & 790 & 790 \\
\hline Number of Households & 125 & 125 & 125 & 125 \\
\hline
\end{tabular}

Note. - Standard errors in parentheses.

* Significant at the 10 percent level.

** Significant at the 5 percent level.

*** Significant at the 1 percent level. 
Time in school

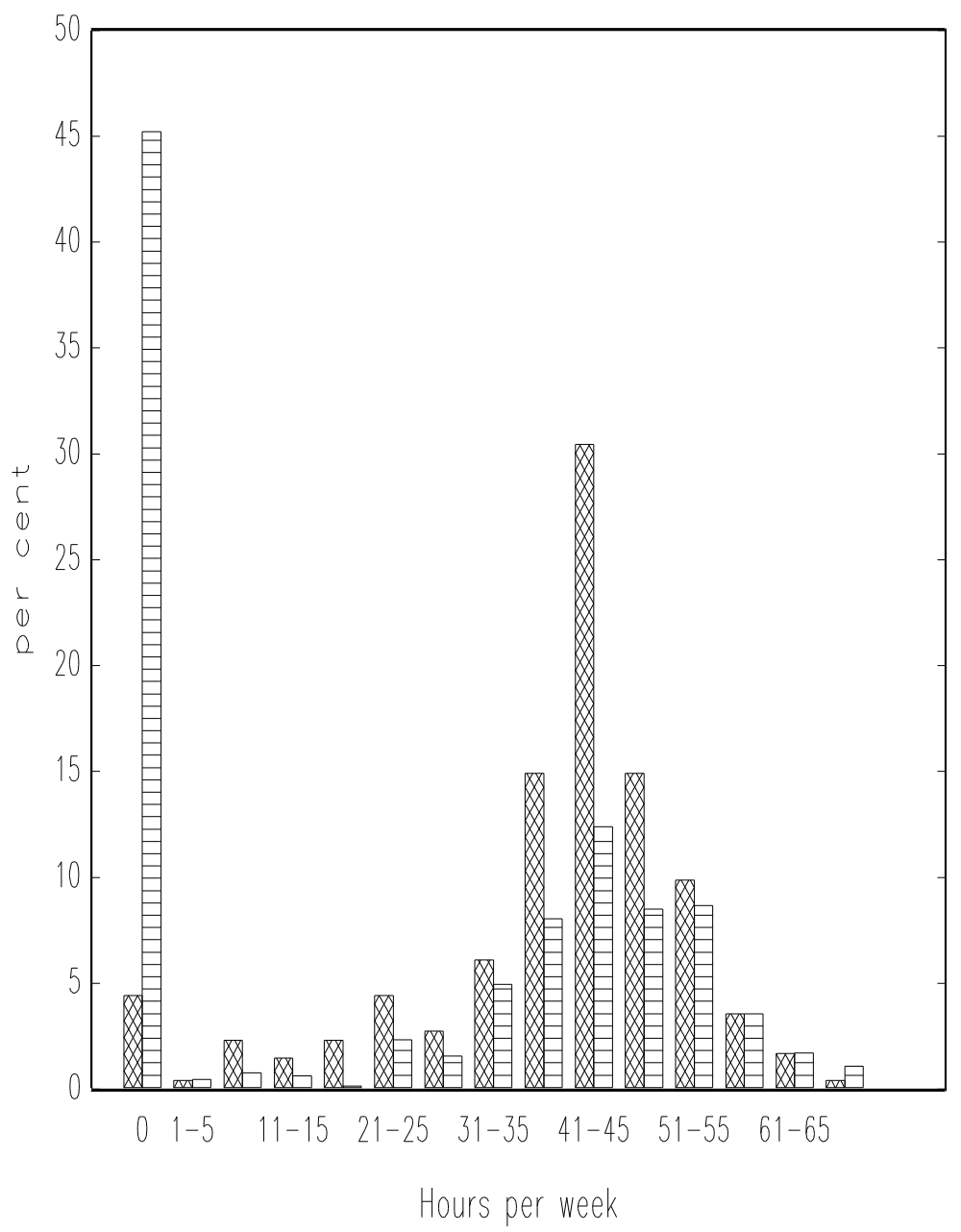

Figure 1: The Distribution of Time Spent on School Activities 